\title{
Damage detection versus Heat dissipation in E-Glass/Epoxy laminated composites under dynamic compression at high strain rate
}

\author{
M. Tarfaoui (1), A. El Moumen (1,*), H. Ben Yahia (1) \\ (1) ENSTA Bretagne, FRE CNRS 3744, IRDL, F-29200 Brest, France. \\ (*) Corresponding author. E-mail address: ahmed.el_moumen@ensta-bretagne.fr
}

\begin{abstract}
:
In this investigation, a new experimental technique in which the deformation, damage mode, and the temperature are measured simultaneously during a high strain rate on laminated composites materials. The composites consist of unidirectional E-glass fibers reinforced epoxy polymer composites used in industrial applications. The experimental setup consists of a compression Split Hopkinson Pressure Bar (SHPB), a high-speed infrared camera and a high-speed Fastcam rapid camera. Specimens, with cubic like a shape, are impacted at different strain rates ranging from 200 to $2000 \mathrm{~s}^{-1}$. During impact test, the specimen surface is controlled and monitored with the infrared camera which provides thermal images in time sequence and with high-speed camera which acquires the damage progressive in specimens. Experimental results show that the damage throughout specimens differs and the temperature change depending on the damage mode and their maximum exceed $219^{\circ} \mathrm{C}$.
\end{abstract}

Keywords: Hopkinson Bars; Dynamic compression test; Composite materials, Damage, Heat dissipation. 


\section{Introduction}

Composite materials were used in various industrial applications including aircraft, civil infrastructures, military and systems for the recovery of renewable energies like wind turbine blades due to superior mechanical properties. But using composite structures for these applications are generally subjected to high deformation causing damage of constituents in different forms, which in turn cause heat dissipation [1]. Hence, a thermomechanical analysis, with control of the temperature profile during loading test, was needed in order to better describe the dynamic behavior.

Monitoring of the composite response during dynamic load is possible with an infrared imaging system. In particular, the infrared camera can be used to account for thermal effects which develop during an impact event. For fiber reinforced polymers, the infrared imaging system has been mainly used for damage evolution assessment [2]. Some preliminary results, which were obtained by monitoring with the infrared camera the thermal behavior of glass fiber/polymer composites under impact load, were presented by Meola and Carlomagno [3]. It has been proved that the choice of the appropriate sampling rate makes possible to appraise thermo-mechanical effects under low energy impact. An experimental procedure was developed by Kordatos et al. [4] in order to determine and to control the crack growth rate using thermographic mapping of the material. The obtained results concerning crack growth were found to be in agreement with measurements obtained by the conventional techniques. Temperature measurements of specimens during a tensile SHB have been proposed by Noble and Harding [5]. A maximum temperature measured is in the range of $240-310^{\circ} \mathrm{C}$ at a nominal strain rate of $1600 \mathrm{~s}^{-1}$. For polymeric materials, Arruda et al. [6] studied the variation of the temperature in polymethyl methacrylate (PMMA) deformed at low to moderate rates using an infrared method. This technique of characterization has also been introduced by Buckley et al. [7], Garg et al. [8], Lerch et al. [9], Li and Lambros [10], Mulliken [11], Pan et al. [12] and Regev and Rittel [13] in order to study the heat dissipation which occurs in various polymer materials as PC, PMMA, PVC, BMI, BPA and epoxy neat polymers.

One of the recent examples is the research of Meola et al. (2016) [14], where used the infrared thermography in order to measure the temperature increases in a laminate specimen during Charpy pendulum impact test. Tested composite materials, involving different polymer matrix reinforced with natural flax fibers, were impacted at 10 and 12 Joules of energy and the surface opposite to impact direction is monitored with the infrared camera. The results 
show that through the visualization of thermo-elastic/plastic effects, it is possible to gain more information's useful for the comprehension of the damage mechanisms into matrix and flax fibers reinforcement. This experience shows an abrupt rise in temperature of the composite, from 149 to $161^{\circ} \mathrm{C}$, accounting for fibers breakage. A central hot was appeared in the impacted zone and continues to grow and evolves into an L-shaped structure leaning along the fibers oriented at $\pm 45^{\circ}$.

Investigation the damage evolution in the impacted material, during the drop test, based on active infrared thermography was also studied by Li et al. [15]. The change of heat thermal was presented by the surface temperature recorded in the form of a thermal image. It can be observed that the damaged zone generate a higher temperature distribution compared to other zones of specimens. A hot spot was also observed around the impacted surface. Various investigations focused on the behavior of metallic materials. Temperature measurement during deformation of composite specimens at high strain tensile rate has been mostly done at several points by using infrared detectors. One example is the research by Gilat et al. [16], where an infrared camera was used to measure the temperature increase in a specimen subjected to high strain rate tensile tests. Results from testing specimens made of stainless steel show that the temperature exceeds $300^{\circ} \mathrm{C}$. Tensile tests with simultaneous fullfield temperature and deformation variations at the nominal strain rates of $0.01,0.1,1,200$ and $3000 \mathrm{~s}^{-1}$ were recently presented by Seidt et al. [17]. The test duration varies from $57 \mathrm{~s}$ at the lowest strain rate to $197 \mu$ s at the highest value of the strain rate and the results show the temperature rise at all strain rates. No relation between damage evolution and heat dissipation was presented by authors. The equivalent temperature for each strain rate is: 48, 140, 260 and $375^{\circ} \mathrm{C}$ for $0.01,0.1,1$ and $3000 \mathrm{~s}^{-1}$. Heat transfer vs the rupture of the neat polymer under dynamic compression was studied by Gagnon et al. [18]. The Infrared images provide information about the surface temperature of polymer that can be attributed to the stress response of the polymer and breaking of chemical bounds. For first impact wave, the polymer sample heats homogeneously and a localized heating on both sides of tested specimen takes place. The sample keeps heating as the specimens deform. Heat generation with temperature variation was identified by Pan et al. [19] for polyurethane polymer without reinforcement under dynamic compression. It is found that more heat was generated at higher strain rates because of larger deformation. No evolution of temperature vs type of damage is proposed by authors. 
Several works have studied the variation of the temperature during high rate compression tests using sophisticated contact technique [20]. This technique consists to use a specific instrumentation of thermocouples embedded into specimens in order to monitor in situ the temperature values under dynamic loading. Chou et al. [21] firstly measured the temperature rise during tests using embedded thermocouples. Rabin and Rittel [22] developed a technical analysis of the time response of solid embedded thermocouples and Rittel [23] used the embedded thermocouple technique to investigate the temperature rises of polycarbonate at high strain rates. Michael et al. [24] used a thermocouple method to measure the temperature rise that occurs in the center of specimens undergoing high deformation. If considering the contact technique, it should be noted that it can be intrusive when inserting the thermocouple at the heart of the specimen [25-26], and using this technique, no information regarding damage evolution can be obtained. Due to experimental difficulties, the coupling between the effects of strain hardening, strain rate, and the temperature measurement on the damage of unidirectional laminated composites is rarely discussed for Hopkinson bars compression tests. It has already been demonstrated the usefulness of an infrared camera to control the low velocity impact event of static loading for polymeric and metallic materials, but none of them has studied the heat dissipation phenomenon generated by damage mechanisms during compression SHPB tests for laminate.

The intention, now, is to go on in the investigation attempting to gain more information on the laminated composites by considering Epoxy polymer matrix reinforced with E-glass fibers and subjected to high strain rate compression. The novelty of the study concerns the heat dissipation vs damage evolution during the dynamic compression tests. This technique was initially used for static, fatigue, drop and high strain tensile tests. The dynamic compression presents the various type of damages in which full field temperature measurement can help in determining the variation of heat dissipation vs damage evolution. In this investigation, infrared camera and high-speed camera are used with the help of split Hopkinson bars in order to measure full-field deformation, full-field temperature and to control of damage evolution during a high rate compression test. The attention is devoted to two main aspects: (1) Analysis of temperature variation during impact test to gain more elements about their effect on damage initiation and propagation and (2) evaluation of the effect of strain rate on heat dissipation and damage in laminated composites subjected to dynamic compression with Hopkinson bars. 


\section{Experimental analysis}

\subsection{Description of specimens}

Composite laminates used in this study consists of 2400 Tex E-glass fibers embedded in an epoxy polymer matrix. The reinforcement consists of a plain weave fabric with $90 \%$ warp yarns and $10 \%$ weft yarns. The resin is an EPOLAM pre-polymer, EPOLAM 2020 hardener and 2020 accelerator from Axson. Panels of $500 \mathrm{~mm}$ x $500 \mathrm{~mm}$ were made by infusion process, Figure 1a, with 40 unidirectional layers, stacking sequence of $[ \pm 60]_{20}$ and an overall thickness of $13 \mathrm{~mm}$. The resin distribution over the whole laminate is aided by resin flowing easily through the tissue plies at ambient temperature.

The square specimen was cut into cubic shape, Figure 1b, with dimensions listed in Table 1. Static compression tests are conducted on cubic samples in order to obtain the elastic properties of the lamina. In-plane loading (IP), parallel to the layers plane and out-of-plane loading (OP), according to the thickness (direction 3) were considered. Strain gages were placed on the various facets of samples at different angles to measure the strain inside the specimen, Figure 2. Each test was repeated at least three times, and the results are recorded and averaged. The mechanical properties of specimens, obtained with static compression, are given in Table 2.

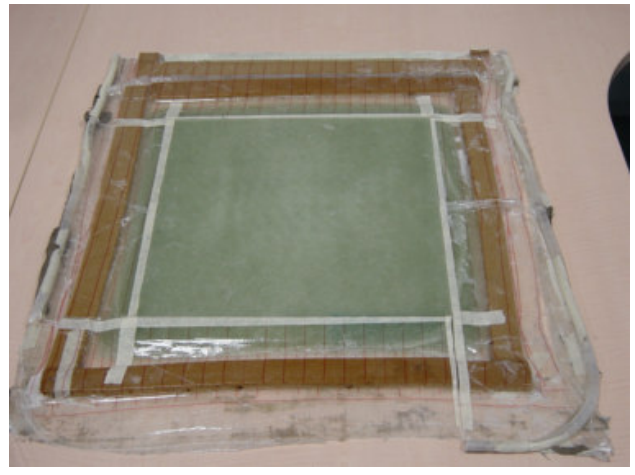

(a) Infusion process

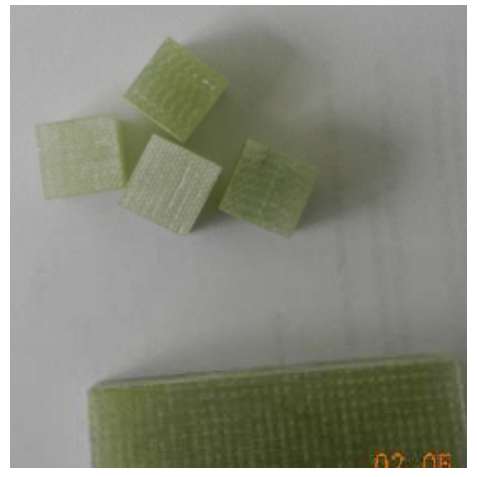

(b) Specimen

Figure 1: Manufactured panels and specimens.

\begin{tabular}{ccccc}
\hline $\begin{array}{c}\text { Thickness, } \\
(\mathbf{m m})\end{array}$ & $\begin{array}{c}\text { Surface } \\
\left(\mathbf{m m}^{2}\right)\end{array}$ & $\begin{array}{c}\text { Void fraction } \\
(\boldsymbol{\%})\end{array}$ & $\begin{array}{c}\text { Stacking } \\
\text { sequence }\end{array}$ & $\begin{array}{c}\text { Fiber volume } \\
\text { Fraction }(\boldsymbol{\%})\end{array}$ \\
\hline $13.00(0.1)$ & $13 \times 13(0.2)$ & 1.78 & {$[ \pm 60]_{20}$} & $55.0(0.5)$ \\
\hline
\end{tabular}

Table 1: Geometry and fiber mass fraction of samples, the standard deviation between brackets. 


\begin{tabular}{lccccc} 
& Test\#1 & Test\#2 & Test\#3 & Mean & Std. Dev. \\
\hline $\mathbf{E}_{\mathbf{1}}(\mathbf{M P a})$ & 46140 & 46130 & 46381 & 46217 & 142 \\
$\mathbf{E}_{\mathbf{2}} \mathbf{( M P a )}$ & 16120 & 16090 & 16048 & 16086 & 36 \\
$\mathbf{E}_{\mathbf{3}} \mathbf{( M P a )}$ & 9100 & 9125 & 8961 & 9062 & 88 \\
$\mathbf{G}_{\mathbf{1 2}}(\mathbf{M P a})$ & 2150 & 2245 & 2277 & 2224 & 66 \\
$\mathbf{G}_{\mathbf{2 3}} \mathbf{( M P a )}$ & 4499 & 4569 & 4552 & 4540 & 36 \\
$\mathbf{G}_{\mathbf{1 3}} \mathbf{( M P a )}$ & 3430 & 3510 & 3560 & 3500 & 66 \\
$\mathbf{V}_{\mathbf{1 2}}$ & 0,29 & 0,284 & 0,266 & 0,28 & 0,012 \\
$\mathbf{V}_{\mathbf{2 3}}$ & 0,088 & 0,099 & 0,104 & 0,097 & 0,008 \\
$\mathbf{v}_{\mathbf{1 3}}$ & 0,421 & 0,413 & 0,396 & 0,41 & 0,012 \\
\hline
\end{tabular}

Table 2: Mechanical properties of composites used for experimental characterization.

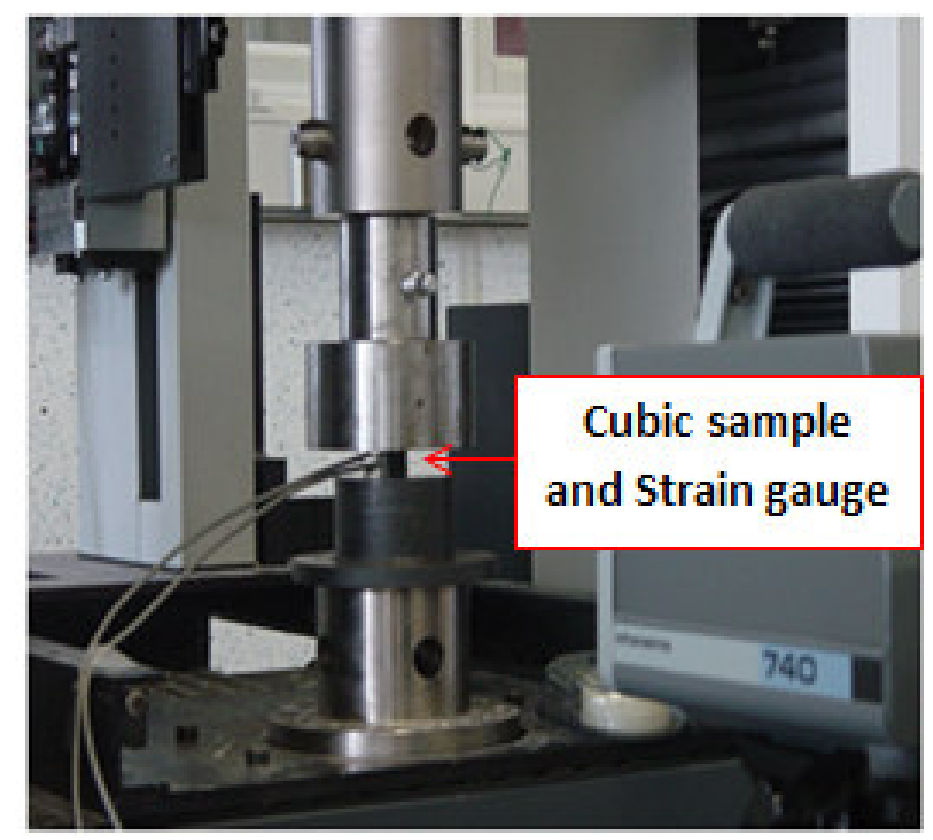

Figure 2: Static compression test of cubic samples and fixtures system.

\subsection{Test procedure}

Tests are performed with the help of SHPB installed at the research center of ENSTA Bretagne, Figure 3, at different strain rate ranging from 200 to $2000 \mathrm{~s}^{-1}$. The SHPB mainly consists of an incident and transmitted bars, made of hardened steel with a diameter of 20 $\mathrm{mm}$. The compression loading wave is generated by a striker impactor tube that impacts a flange at the far end of the incident bar. The full-field deformation during the impact tests is determined by using strain gauges. The photograph shown in Figure 3 shows a view of the experimental test machines. All of the tests are carried out according to the fibers direction of 
$\pm 60^{\circ}$. High-speed camera, with a maximal capacity of $100000 \mathrm{f} / \mathrm{s}$ is installed in front of impact chamber in order to track the initiation and propagation of damage. The thermal acquisition is measured with the help of FLIR SC7000 camera characterized by thermal resolution of $25 \mathrm{mK}$ and acquisition frequency fixed to $2 \mathrm{kHz}$. The data recording is treated by Altair software. The specimens, with a cubic shape, are placed between bars as shown in Figure 4.
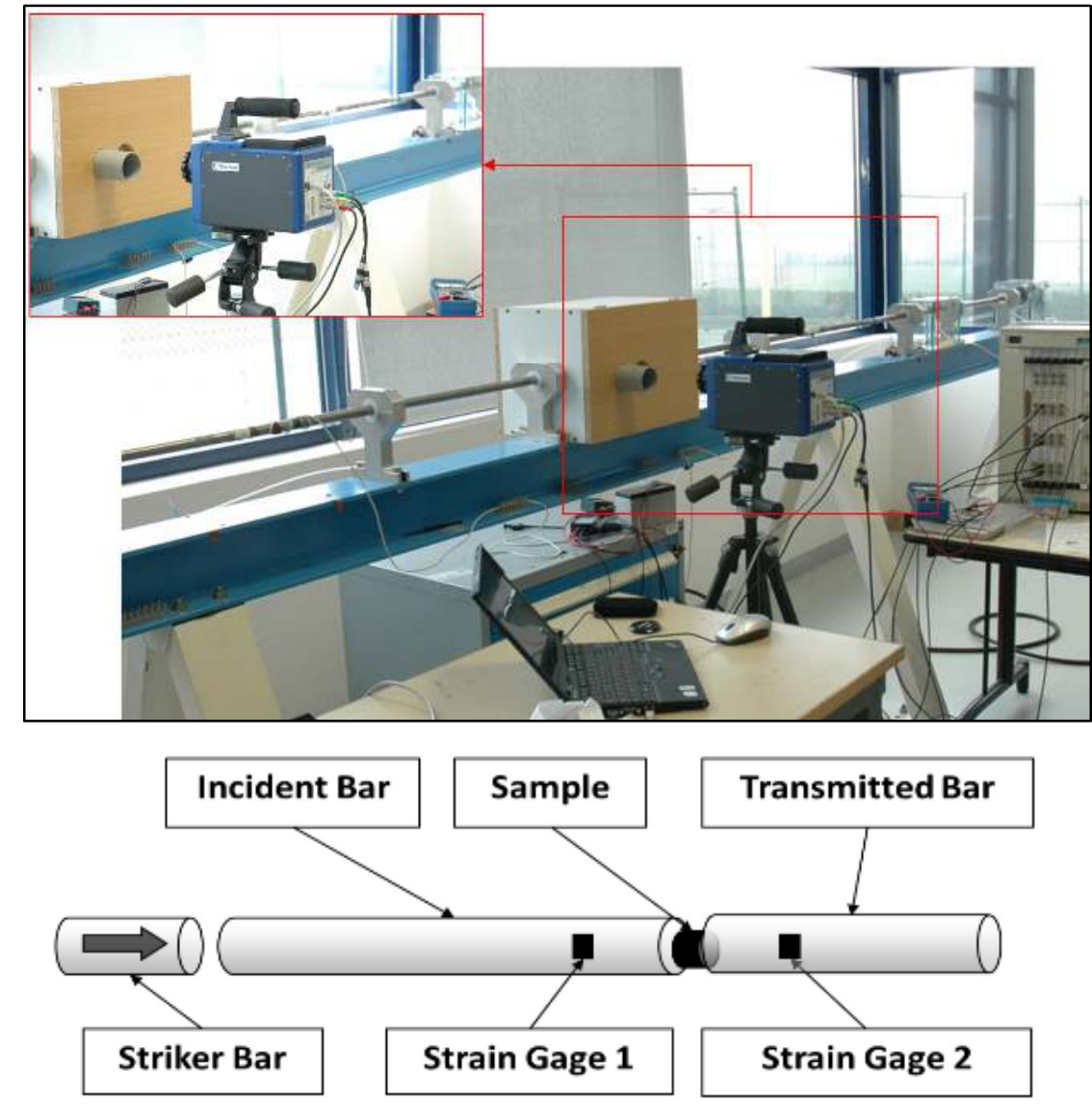

Figure 3: SHPB tests with full-field deformation and temperature measurements.
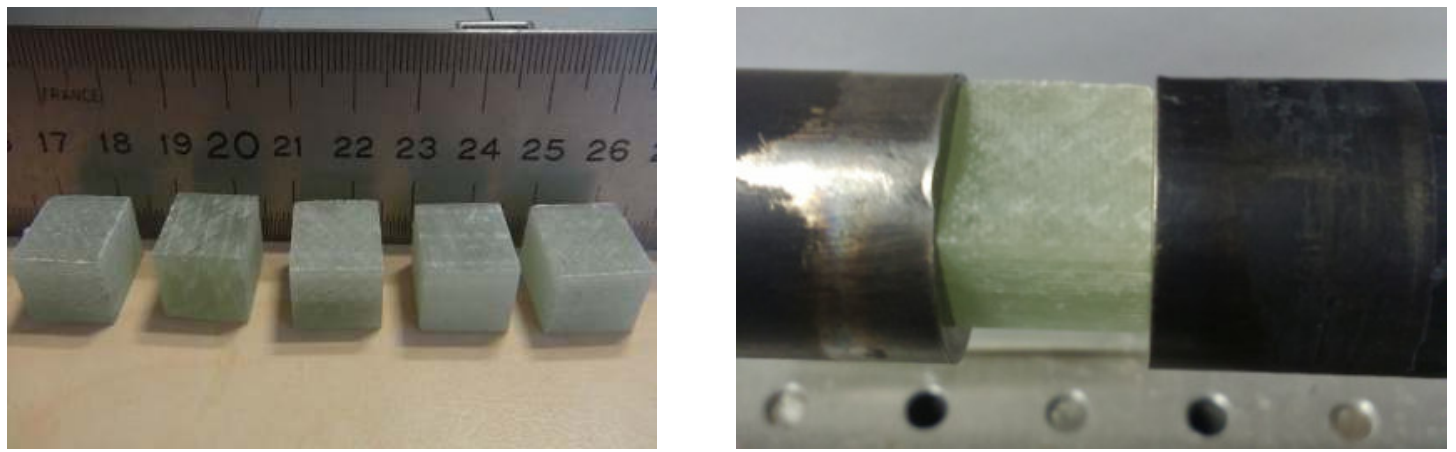
Figure 4: Specimen dimensions and fixture system.

\section{Results and discussion}

To ensure the reproducibility of experimental data, 5 tests will be carried out for each impact pressure (strain rate). The tests were performed at ambient temperature. The dynamic responses and the thermal dissipation are controlled as a function of damage initiation and evolution.

\subsection{Dynamic response of composite panels}

In this dynamic compression tests, a cubic sample is placed between the two bars with same diameter $20 \mathrm{~mm}$. The striker, incident and transmitted bars have a length of $0.8,3$ and $2 \mathrm{~m}$, respectively. These bars are correctly aligned and are able to slide freely on the base. The composite is not attached to the bar in order to prevent perturbations of measurements due to additional interfaces. The signals were treated with Maple Software using Fast Fourier Transformation to obtain the evolution of dynamic characteristics: Stress-strain, strain rate, load and velocities. The specimens were subjected to different impact pressure, and the resulting signals were recorded by a digital oscilloscope. For each test, a minimum of five tests were achieved for each pressure in order to verify the test reproducibility. Figure 5 gives an example of the typical signals obtained during a test carried out with the Hopkinson bars. This figure shows an example of the obtained signal as a function of impact time for a striker velocity equal to $12.5 \mathrm{~m} / \mathrm{s}$. It should be noted that the obtained curve is similar to one of Hopkinson bars which composed with the incident, transmitted and reflected waves. Upon impacting the input bar, the striker creates a compressive wave that traveled along the input bar. In the case shown below, the incident and the transmitted signals are given at the center of each bar. After $0.15 \mathrm{~ms}$, from the time impact, the compressive wave arrives at the middle of the input bar. At $0.58 \mathrm{~ms}$, a fraction of the wave is reflected at the input-bar free surface as a tensile wave. Due to the gap between the two bars, the input bar took approximately $0.1 \mathrm{~ms}$ to reach the output bar and the duration of the transmitted wave was shorter than the incident wave. The duration of the incident wave is $0.4 \mathrm{~ms}$. 


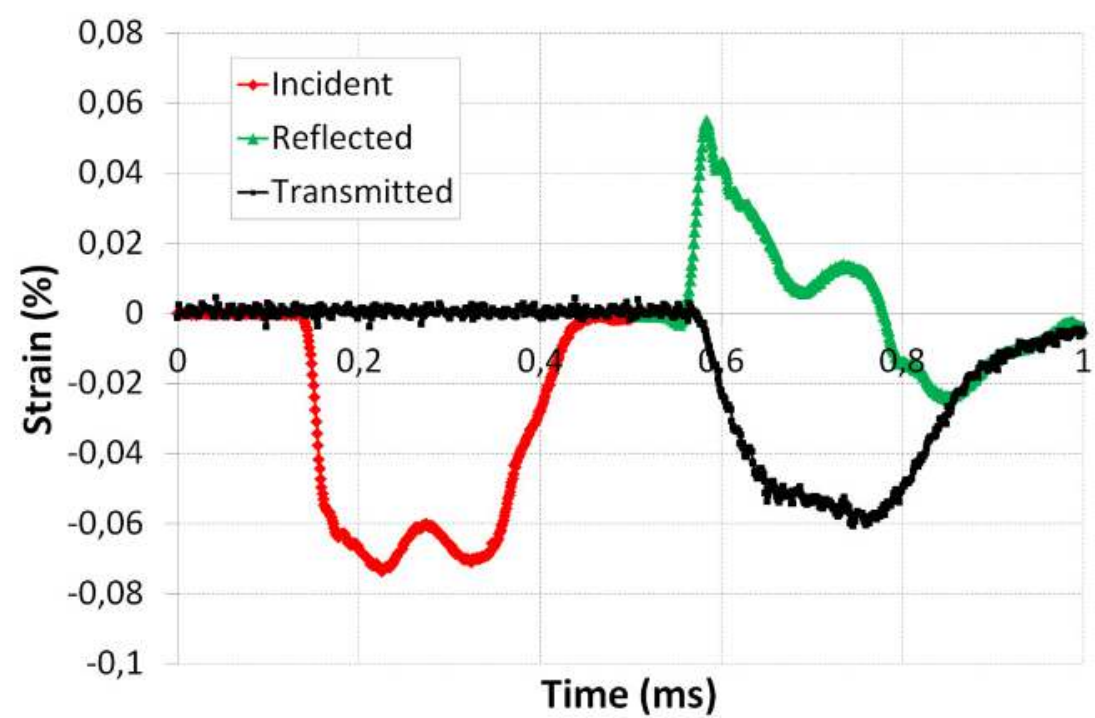

Figure 5: Typical incident, reflected and transmitted pulse, $[ \pm 60]_{20}$ and $\mathrm{P}=0.9 \mathrm{bar}\left(831 \mathrm{~s}^{-1}\right)$.

Furthermore, the input signals (in voltage) are converted to the average stress of the specimen via multiplying by the stress scale factor. Then the strain rate versus time and stress-strain curves can be obtained. Figure 6 shows the strain rate - time histories using different impact pressures (or different impact energy). These tests are conducted at laboratory temperature. The magnitude and duration of waves increase with the impact pressure. It is seen that the pulse is approximately $0.35 \mathrm{~ms}$ long for $1.6 \mathrm{bar}$ and characterized by a trapezoidal shape, with a flat region, and by a decaying tail.

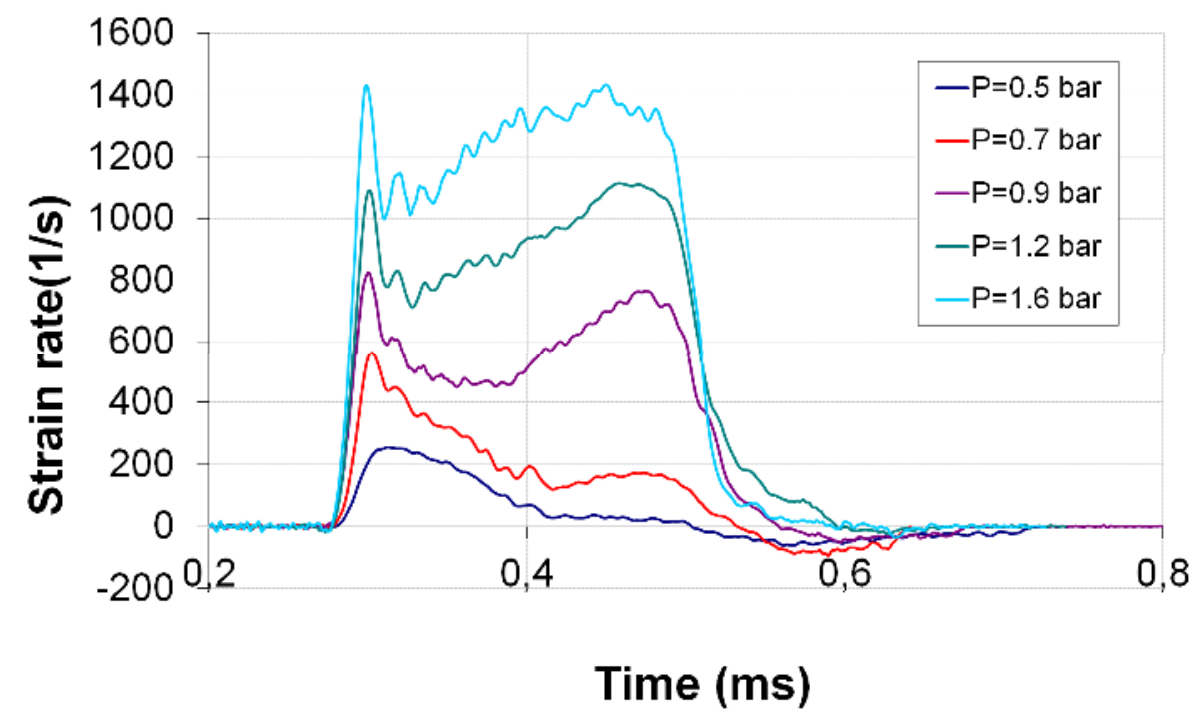

Figure 6: Strain rate vs. time for different impact pressures. 
Figure 7 shows the Stress-Strain curve obtained by impacting the specimens approximately with the same impact energy, $\mathrm{W}=11 \mathrm{~J}$, to ensure the reproducibility of the experimental procedure. It appears that all of the curves have a mountain-like shape and exhibit approximately the same trends. The three tests found the same maximum stress, 210 $\mathrm{MPa}$, for the same strain, $1.65 \%$.

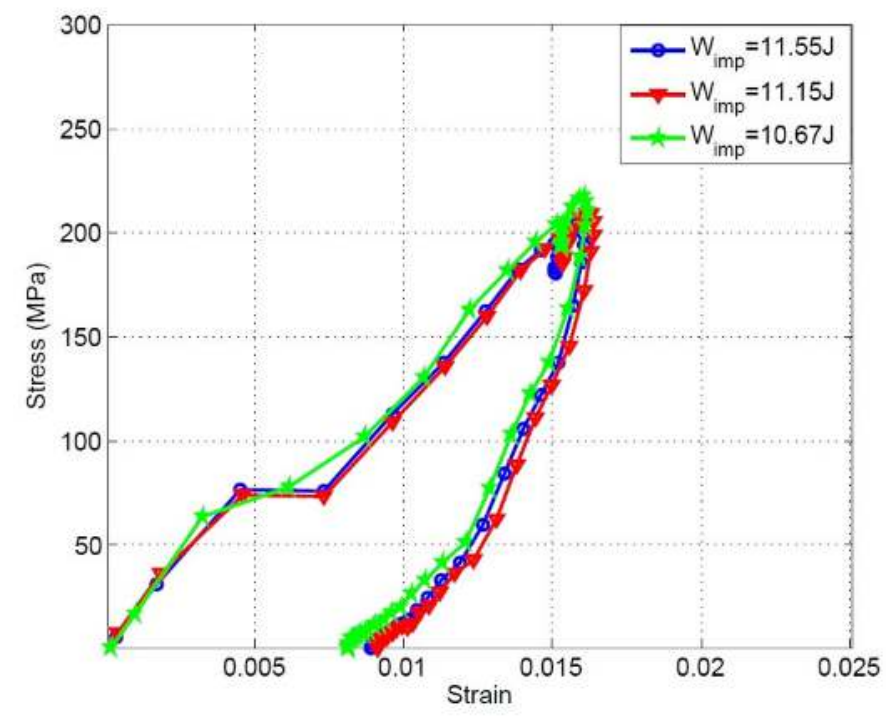

Figure 7: Reproducibility of experimental test.

Now, the tests were done at strain rates ranging between 200 and $1500 \mathrm{~s}^{-1}$ at ambient temperature. It follows from Figure 8 that the stress increases with increasing strain rate. The strain rate exerts a significant effect on the dynamic properties of composites subjected to Hopkinson bars. 


\section{ACCEPTED MANUSCRIPT}

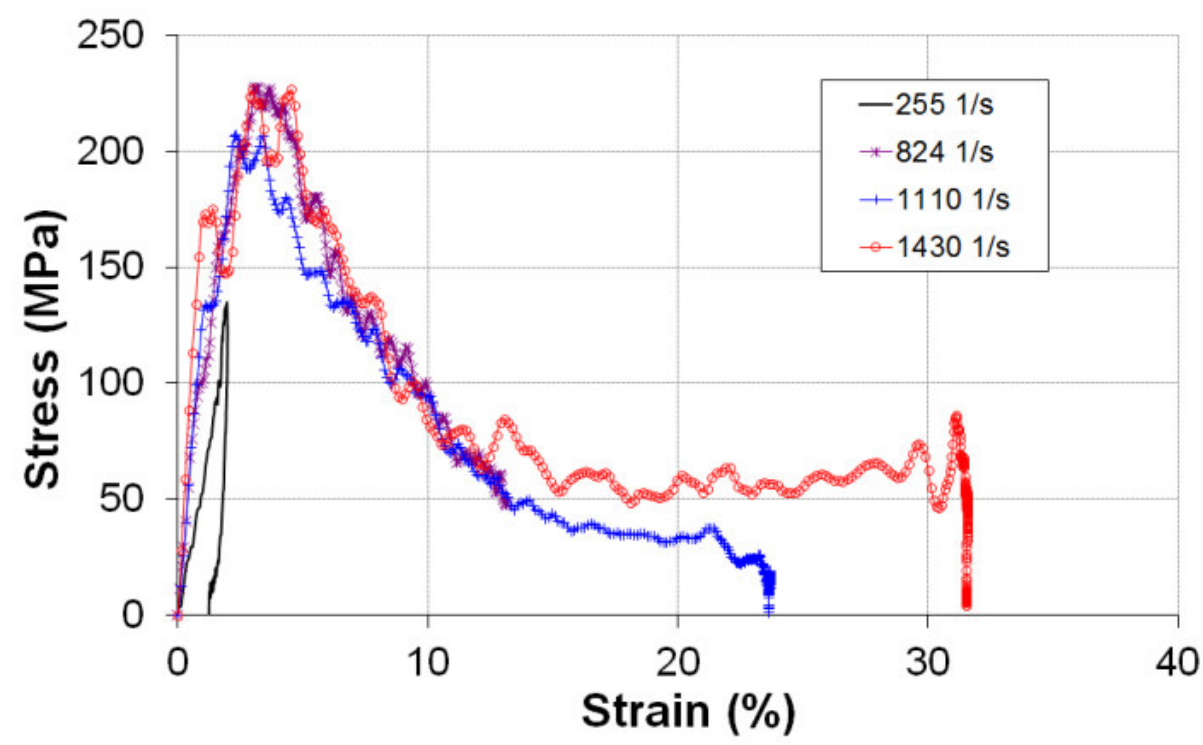

Figure 8: Stress-strain curves, $\mathrm{T}=24^{\circ} \mathrm{C}$.

We can also note that for strain rates less than $255 \mathrm{~s}^{-1}$, the damage is not present. On the other hand, when the strain rate exceeds $800 \mathrm{~s}^{-1}$, the damage becomes important and appears. Therefore, strain rate more than $800 \mathrm{~s}^{-1}$ was used in order to control the evolution of damage vs heat dissipation and vs temperature profile.

\subsection{Evaluation of damage mode in tested specimens}

This section is concerned with analysis and discussion of the apparition of damage in the specimens during impact tests. Considering, for example, the case of specimens impacted with 0.8 and 1.6 bar, corresponding to 800 and $1430 \mathrm{~s}^{-1}$, respectively. Figure 9 shows the impacted specimens. In these cases, three types of damage were observed: delamination, cracks in the plies direction and debonding. It appears from this figure that, for different strain rates, the damaged zone has the V-letter like-shape and propagates in the direction of fibers. The damaged zone becomes important for high strain rate, $1430 \mathrm{~s}^{-1}$, and this case is considered and analyzed for thermal analysis.

The evolution of damage in impacted specimens generates a shearing mode between the $\mathrm{V}$ zone and the rest of the specimen. Under the dynamic compression, there is also a buckling mode of the external layers resulting in local delamination for $800 \mathrm{~s}^{-1}$ (0.8bar) and total delamination of ply for the case of $1430 \mathrm{~s}^{-1}$ (1.6bar). The history of damage is given in Figure 10 for different impact times. At the end of the test, a great deformation is observed in 
the transverse direction and generates a separation of N-layers. The V-shape damage form can be observed in the incident bar side or in the transmitted bar side or both, Figures 10A, 10B and $10 \mathrm{C}$.

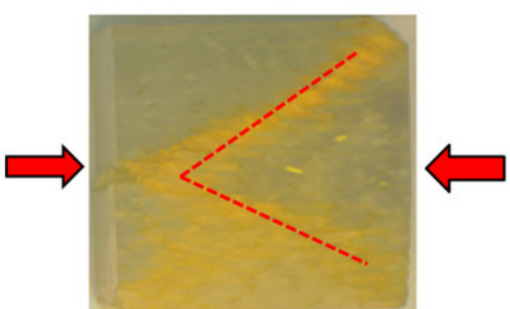

(a) $P=0.8 b a r\left(800 s^{-1}\right)$

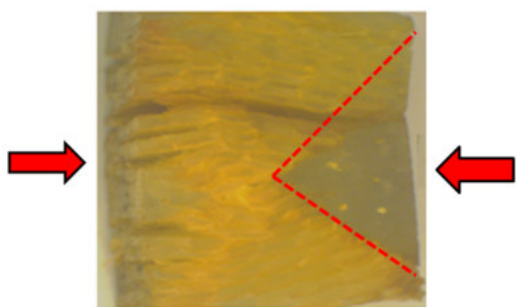

(b) $P=1.6 \operatorname{bar}\left(1430 \mathrm{~s}^{-1}\right)$

Figure 9: Damaged zone under dynamic compression test with Hopkinson bars.

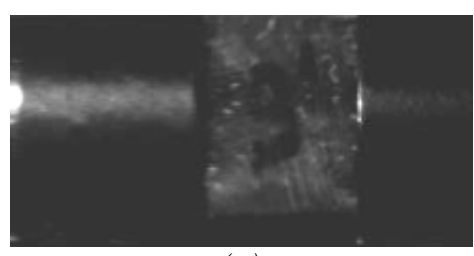

(a)

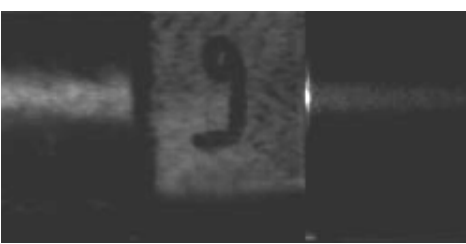

(a)

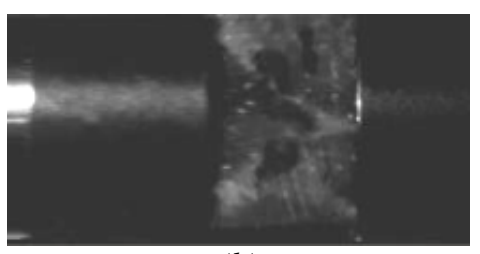

(b)

(A) First scenario of damage

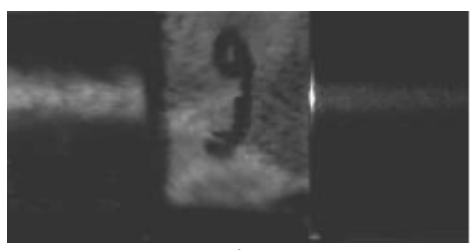

(b)

(B) Second scenario of damage

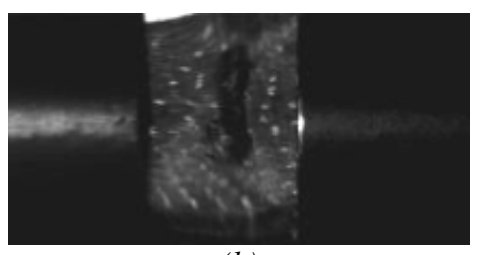

(b)

(C) Third scenario of damage

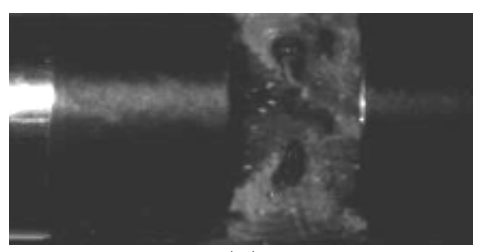

(c)

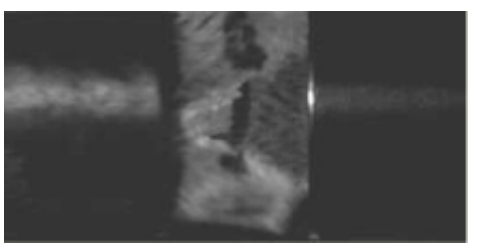

(c)

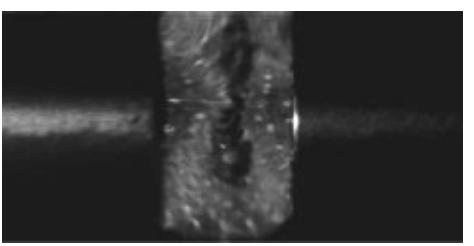

(c)

(a)

Figure 10: The visual image of different modes of damage under Hopkinson bars. 
The damage kinetics of $[ \pm 60] 20$ laminate is summarized in Figure 11. The different damage modes observed are:

- (1) Formation of the $1^{\text {st }}$ damaged zone (V shape, Shear mode: local buckling, fiber kinking and matrix crack).

- (2) "V" emerges by the creation of delamination.

- (3) Formation of the $2^{\text {sd }}$ damaged zone (V shape).

- (4) Delamination (layers block separation) and total failure.
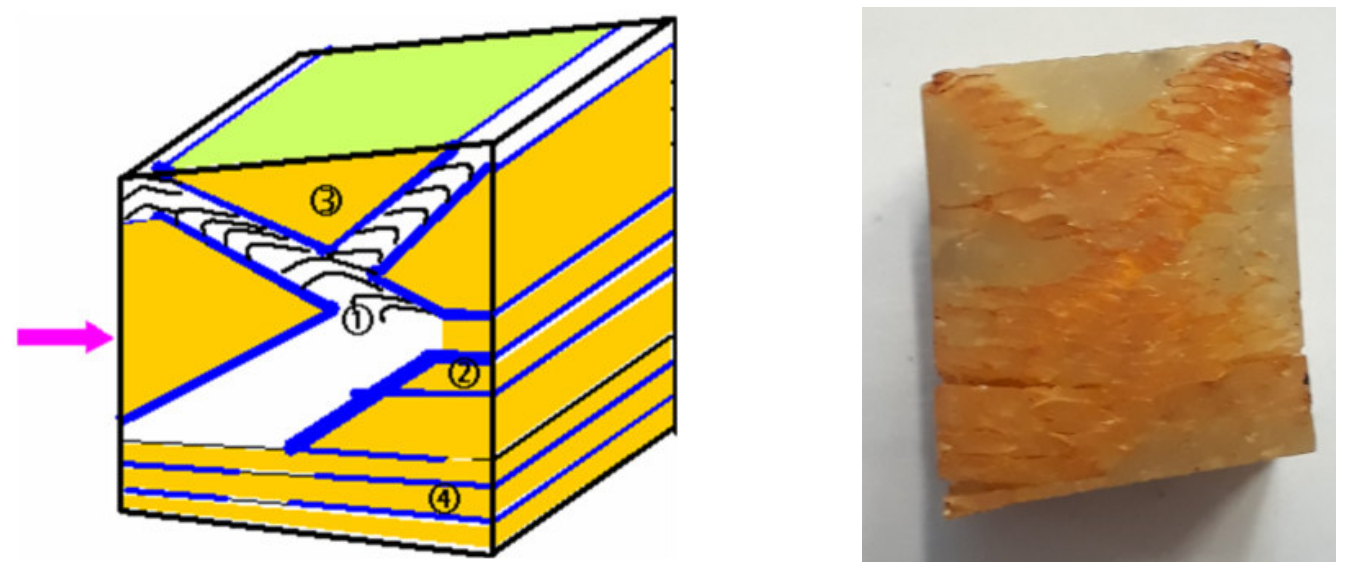

Figure 11: Damage history of $[ \pm 60]_{20}$ cubic sample at high impact pressure.

\subsection{Damage evolution vs heat dissipation}

In order to characterize the dependence of the thermal dissipation on the damage, dynamic compression tests with SHPB apparatus are carried out with the positioning of the infrared camera to view the specimen surface opposite to that of impact. As mentioned, the purpose of this was to determine what the damage type including delamination and cracks generate a higher thermal dissipation. Sequences of thermal images are acquired at $2 \mathrm{kHz}$ frame rate during an impact event. Each sequence of thermal images is post-processed in order to extract the corresponding temperature variations. The variation of temperature is taken in seven positions; namely: higher-line (HL), Middle-Line (ML), Lower-Line (LL), Right-Line (RL), Center-Line (CL), Left-Line (LeL) and Full-Window (FW), Figure 12. 


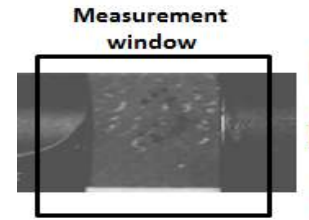

HL : Higher Line

ML : Middle Line

LL: Lower Line

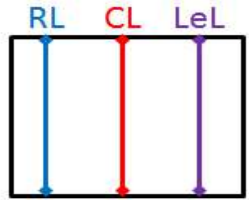

RL: Right Line

$C L:$ Center Line

LeL: Left Line
FW

FW: Full Window

(a) Position of measurement

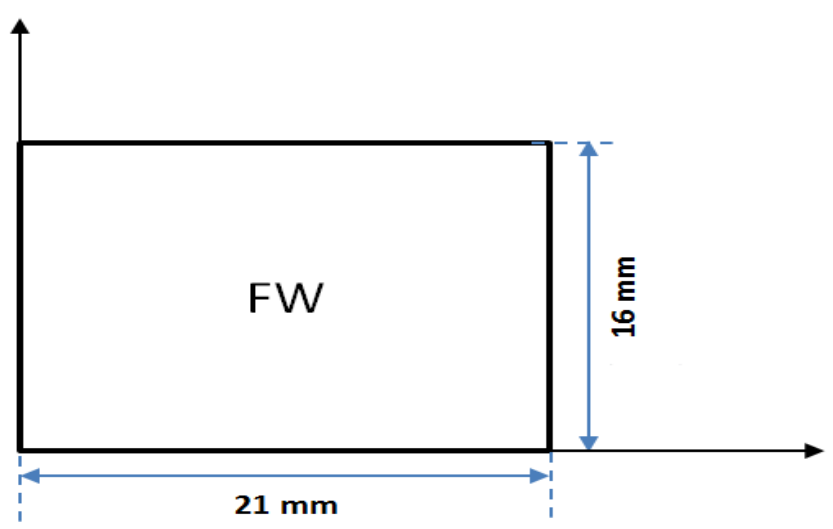

(b) Geometry of measurement area

Figure 12: Heat dissipation measurement area.

An example of the temperature variation at the early part of the tests with the localized damage and heating during the deformation of specimens is illustrated in Figure 13. Quantitative data extracted from the thermal images is displayed and plotted. The temperature variation along the ML of the specimen before impact, $0 \mathrm{~ms}$, and after first wave compression at $0.2768 \mathrm{~ms}$ of impact time is compared. The first image, which was taken just before the impact, displays an overall uniform distribution of temperature being related to room temperature $\left(24^{\circ} \mathrm{C}\right)$. At the arrival of the first compression wave, $0.2768 \mathrm{~ms}$, the specimen experiences a sudden cooling down (dark zones) because of the elastic material expansion [27]. In the thermal image of impacted specimens, a central hot spot appears being due to the dissipation effect with damage growth throughout impact direction. From the latter, it is possible to see that for $1430 \mathrm{~s}^{-1}$ (1.6bar), at $0.2768 \mathrm{~ms}$, a rise in temperature is observed and significant heat dissipation is present and the temperature exceeds $34^{\circ} \mathrm{C}$.

For the same specimen and for the $2^{\text {nd }}$ compressive wave, a series of thermal images taken at different time instants for E-glass/Epoxy specimens tested with $11 \mathrm{~J}$ of impact energy are shown in Figure 14. In the thermal images, it appears that the thermal profile takes also Vletter like shape as the case of damage evolution. It is possible to see V shape with a slight hot 
spot surrounded by a cold region. The maximum temperature is obtained in the damaged zone and exceeds $75^{\circ} \mathrm{C}$. The cold region is formed by bending under the compressive load, while the hot spot indicates the formation of microcracks and initiation of the delamination [28].

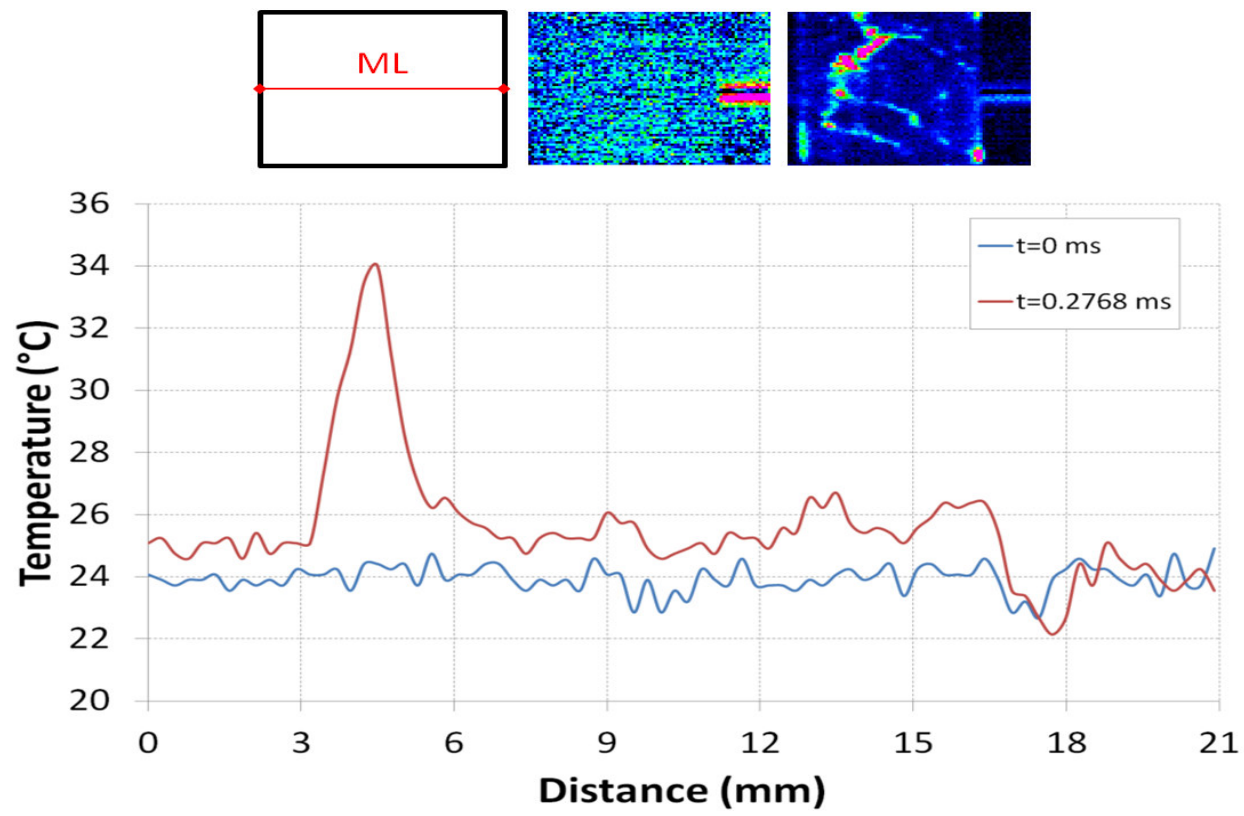

Figure 13: Thermal images recorded by the IR camera and the temperature history at ML, $1^{\text {st }}$ compression wave.
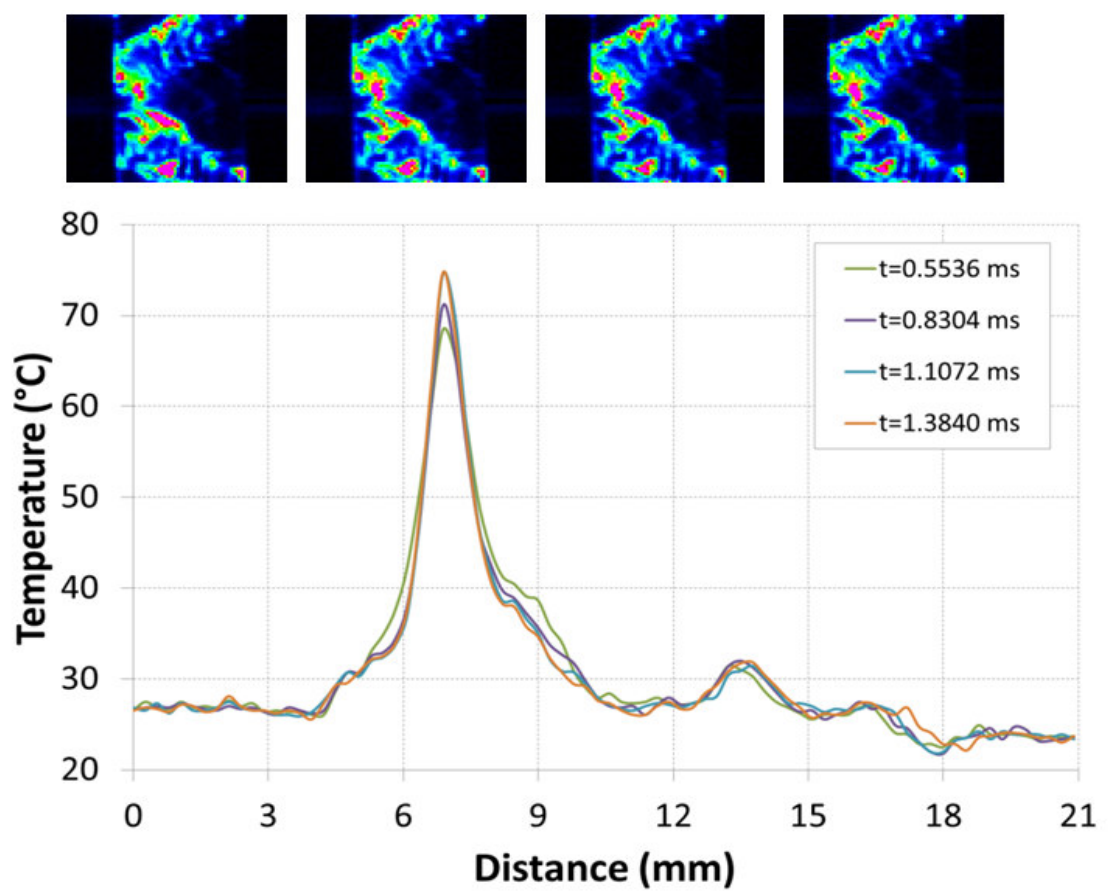

Figure 14: Thermal images recorded by the IR camera and the temperature history at ML, $2^{\text {nd }}$ compression wave. 
The temperature increases with impact time and reached its maximum peak, $190^{\circ} \mathrm{C}$, at 2.7680ms, Figure 15. Hot spots enlarge and another appears forming a unique hot zone localized in the two branches of $\mathrm{V}$, meaning that some important damages have locally occurred in the $\mathrm{V}$ branch and shearing mode is developing between the $\mathrm{V}$ zone and the rest of the specimen. The final hot spot takes V-shape follows the delamination evolution and failure of plies. Temperature increases from $75^{\circ} \mathrm{C}$ to $190^{\circ} \mathrm{C}$.
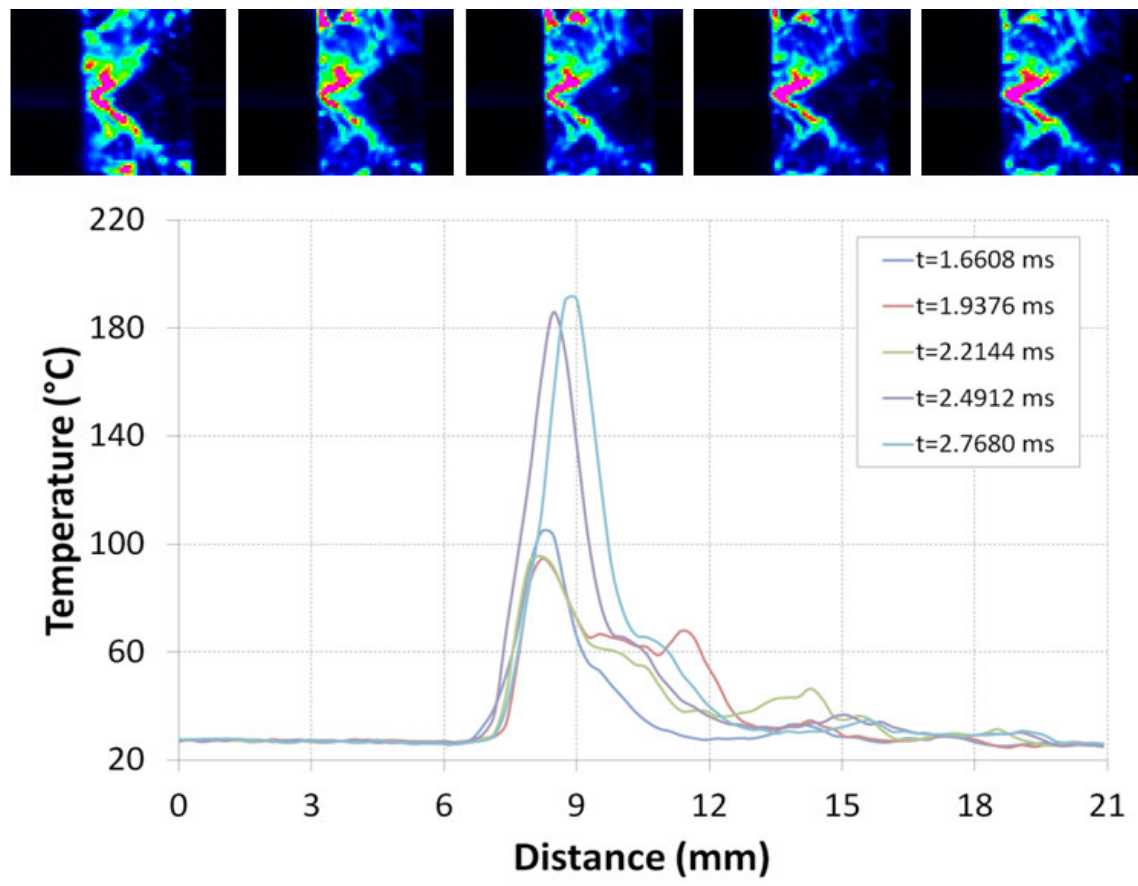

Figure 15: Thermal images recorded by the IR camera and the temperature history at ML, $3^{\text {rd }}$ compression wave.

For more illustration, a contoured thermal and visual image of the specimens under dynamic compression at $1430 \mathrm{~s}^{-1}$ is shown in Figure 16. For comparison, we have reported in this figure a photo of the specimen at the same impact time to show the contoured zone for temperature and damage profiles and the dependence of heat dissipation to damage which appears on composites during dynamic loading. As can be seen, there is a good correspondence between the two areas: the thermal and the visible damage one. In two images (IR vs Camera pictures), the V-letter like shape is observed and the temperature field follows the damage evolution from $0.5536 \mathrm{~ms}$ of impact time. In particular, only different hot spots are present until $1.6608 \mathrm{~ms}$, at which another hot zone configuration is appeared and localized in the center taking V-shape. Then, it is not surprising to see dependence between heat 
dissipation and damage evolution. Going further on in time, all the hot spots coalesce forming a unique V-hot zone. A wider area warmed up is localized in the center of specimens with larger delamination occurred.
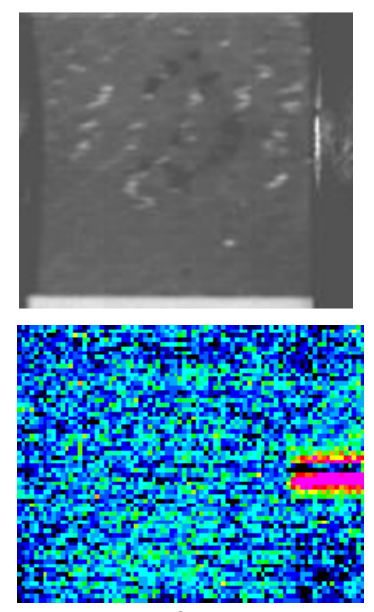

$\mathrm{t}=0 \mathrm{~ms}$
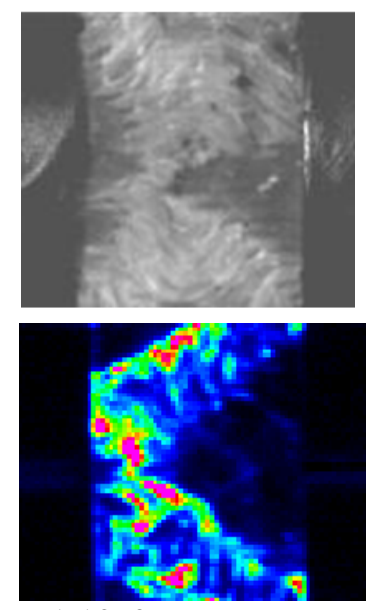

$\mathrm{t}=1.1072 \mathrm{~ms}$
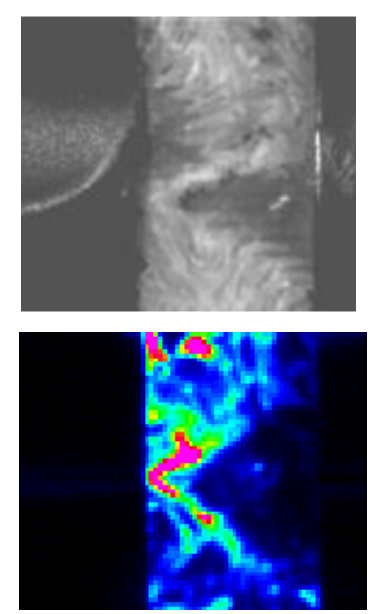

$\mathrm{t}=2.2144 \mathrm{~ms}$
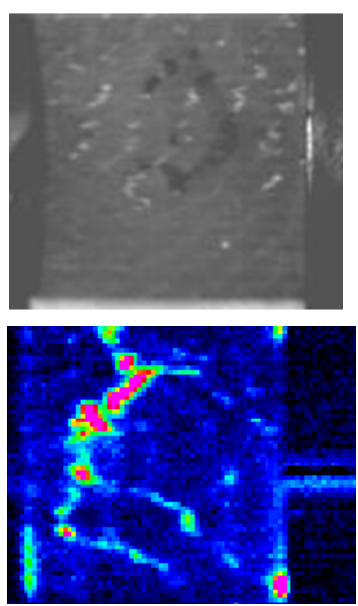

$\mathrm{t}=0.2768 \mathrm{~ms}$
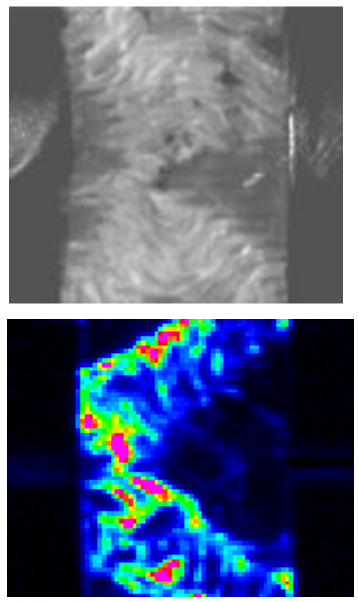

$\mathrm{t}=1.3840 \mathrm{~ms}$
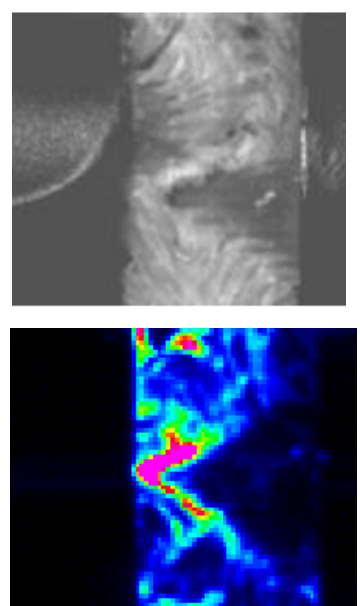

$\mathrm{t}=2.4912 \mathrm{~ms}$
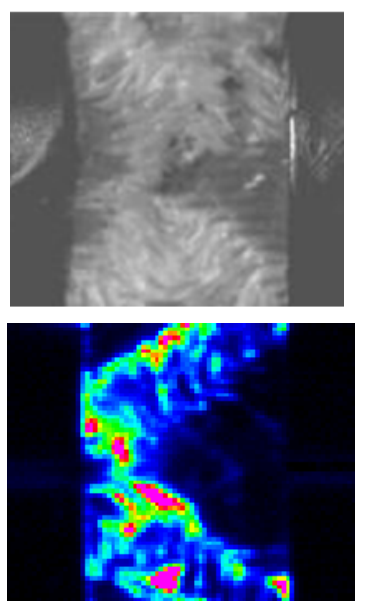

$\mathrm{t}=0.5536 \mathrm{~ms}$
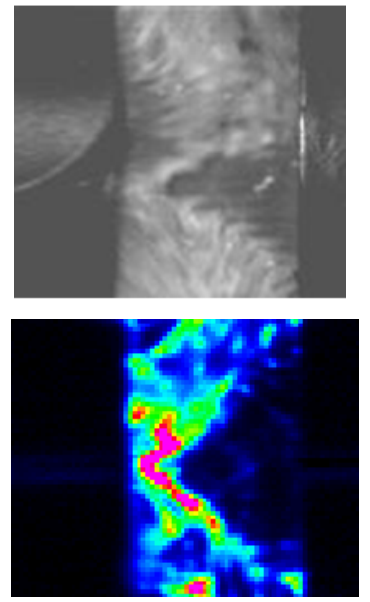

$\mathrm{t}=1.6608 \mathrm{~ms}$
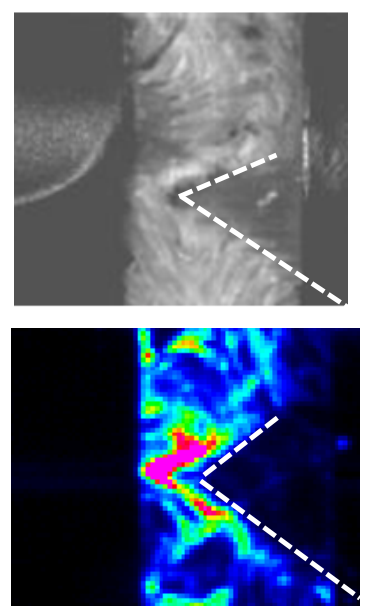

$\mathrm{t}=2.7680 \mathrm{~ms}$
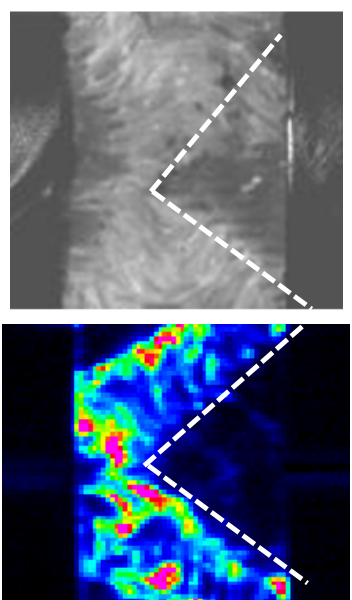

$\mathrm{t}=0.8304 \mathrm{~ms}$
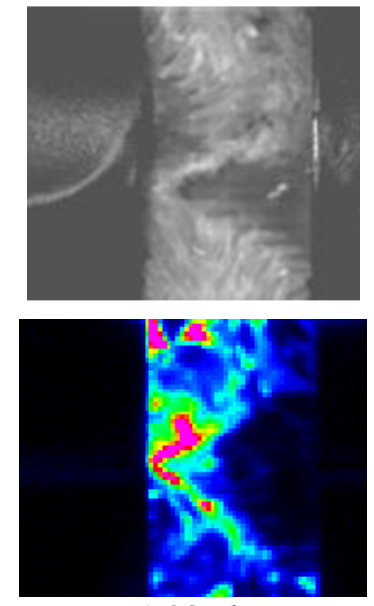

$\mathrm{t}=1.9376 \mathrm{~ms}$

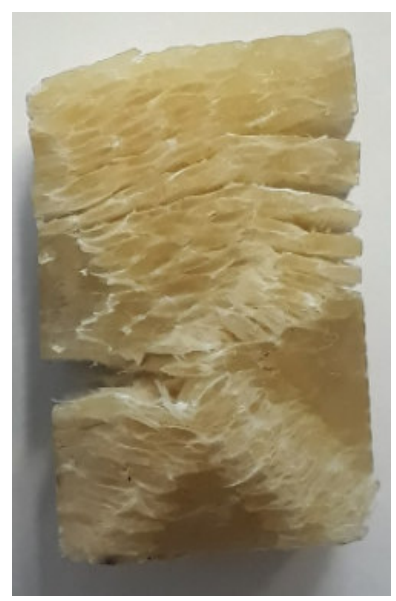

Tested specimen

Figure 16: Thermal and visible images of the specimens impacted at $1430 \mathrm{~s}^{-1}$. 


\subsection{Temperature profile in damaged specimens}

To gain more information about the onset of temperature variation into specimens, the profile is collected in the different zones and a comparison is given, Figures 17 and 18. Six zones, perpendicular and parallel to the direction of compression, were considered as presented in Figures 17 and 18. The uneven distribution of temperature is obvious, and the heat peak is obtained in the center of the specimen where the cracks and delamination become important. In the area of crack defects, the temperature is higher than other areas obviously. Due to the structure of the composite specimen, damaged by dynamic compression tests, the distribution of heat becomes non-uniform throughout the specimen. Significant temperature is located in the damaged area and exceeds $186^{\circ} \mathrm{C}$ in a particular point for horizontal lines. For the perpendicular direction (vertical lines) the peak of temperature exceeds $162^{\circ} \mathrm{C}$.

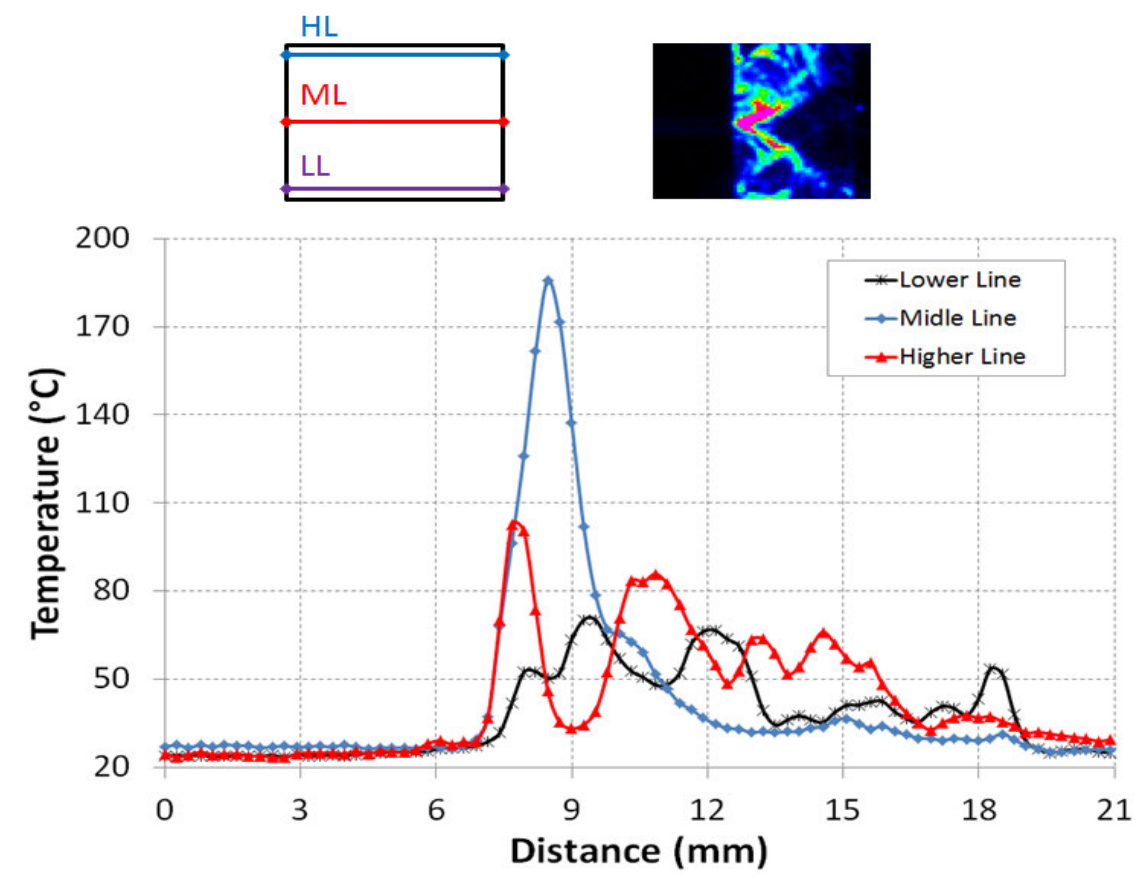

Figure 17: Temperature history for horizontal lines.

For FW zone, the variation of the minimum, the maximum and the mean of temperature during the dynamic compression test for the investigated specimens is reported in Figure 19. As can be seen, the specimen displays an abrupt rise in temperature, at $6 \mathrm{~ms}$, which can be attributed to the combination of different modes of damage observed using a rapid camera and given in [29]. For the full thermal image, the maximum temperature exceeds $219^{\circ} \mathrm{C}$. 

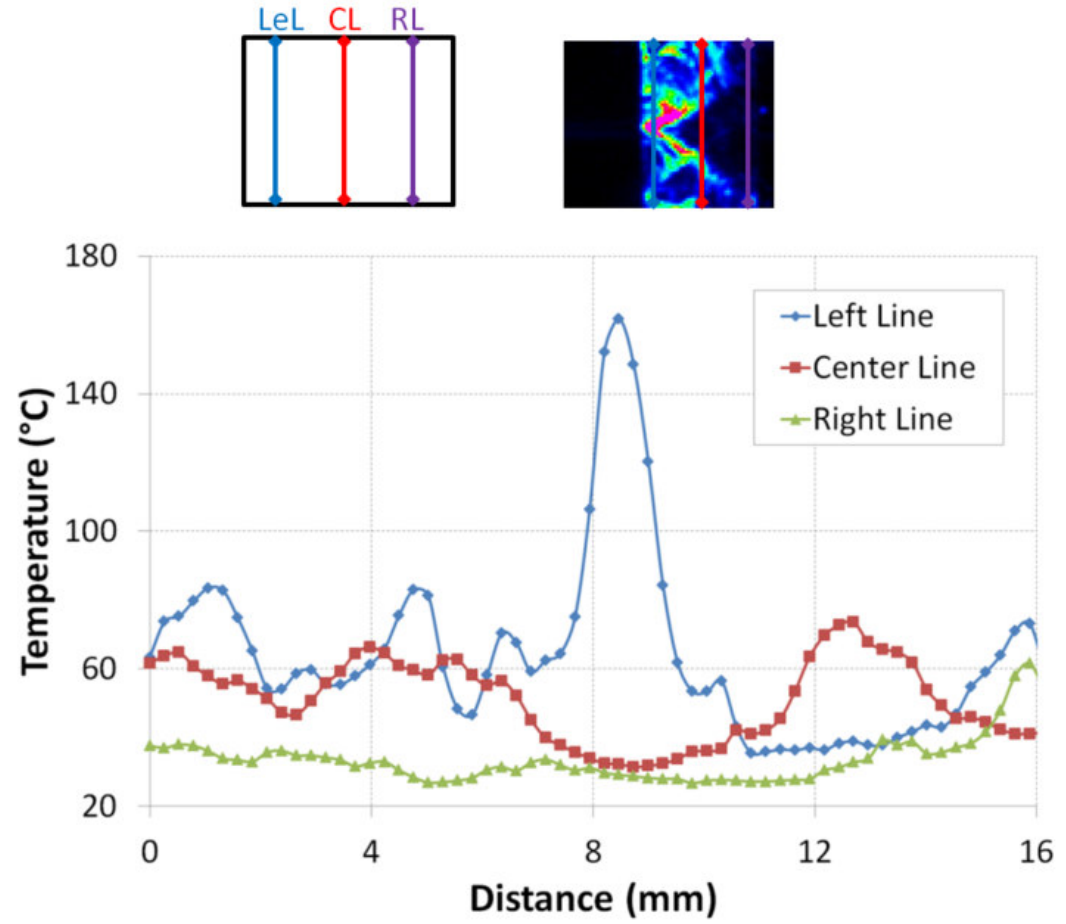

Figure 18: Temperature history for vertical lines.

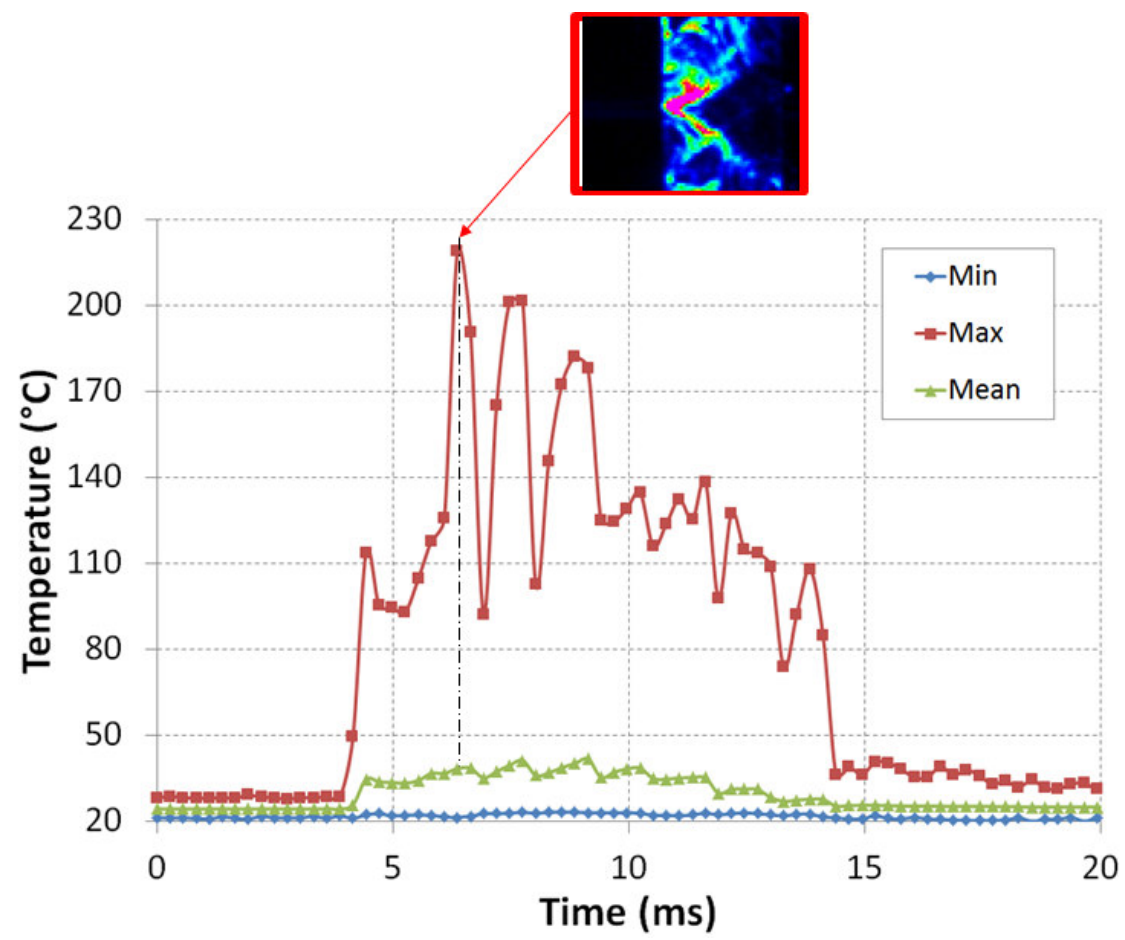

Figure 19: Min, Max and Mean of the temperature profile in FW. 


\section{Discussion}

Composite panels with 40 unidirectional layers, stacking sequence of $[ \pm 60]_{20}$ and an overall thickness of $13 \mathrm{~mm}$ were impacted at different strain rates using Hopkinson bars. Different damage modes were observed into tested panels as for example: local buckling, fiber kinking, matrix crack and delamination. The damage evolution has been investigated simultaneously by the high speed camera and infrared camera. Examination of thermal images clearly indicates the difference in temperature profile throughout impacted specimens. This difference depends mainly on the damage mode. The variation of temperature is taken in different positions of panels. At $\mathrm{t}=0.2768 \mathrm{~ms}$ of impact time, corresponding to $1^{\text {st }}$ compression wave, no surface damage is detected by high speed camera but a heat dissipation is present and the temperature exceeds $34^{\circ} \mathrm{C}$. This change in temperature can be related to the initiation of damage and matrix cracking. For the same specimens, at $t=1.384 \mathrm{~ms}$ of impact time, the temperature continues to be increased and exceeds $75^{\circ} \mathrm{C}$ in the center of specimens. Inspection of this zone with rapid camera and SEM shows the fiber-matrix debonding and matrix cracking, Figure 20a. The fiber-matrix debonding leads to fiber-matrix sliding with friction between fiber surface and polymer which generates a hot spot and an increase in the temperature. The hot zone was localized in the specimen and surrounded the damaged area. In the area of crack defects, the temperature is higher than other areas obviously [30]. At $t=2.768$ ms of impact time, rapid camera shows an important delamination with block separation and total failure, promoting more friction. At this stage, impact test causes the sliding of composite plies, Figure 20b, which generates a hot surface. In addition, severe friction between yarns, plies and the debris of composites also increases the material temperature. Lee et al. [31] and Cheeseman et al. [32] show that the yarn pull-out and the friction between the yarns themselves are responsible for how much energy is absorbed with heat release. Specimens at the ends of tests are illustrated in Figure 20c showing sliding and shear in composite plies. Total failure and breakage were obtained. From previous works, failure may occur with development of greater heat dissipation [27,33] and the impact energy was transformed to heat energy, which results in the instantaneous increasing of temperature variation in the local area [34]. For $[ \pm 60]_{20}$, tested specimens, the equivalent thermal image indicates an elevation in the temperature of specimens from 75 to $190^{\circ} \mathrm{C}$. According to [35, 36] important deformation leads to the large temperature rise during the heating stage around the cracked areas and the maximum heat was observed when crack depth is larger. 


\section{ACCEPTED MANUSCRIPT}

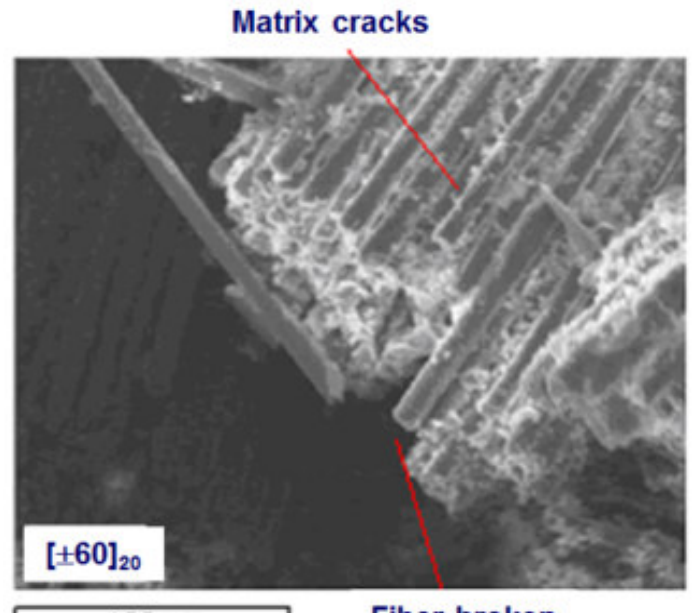

$100 \mu \mathrm{m}$

(a) Damage in constituents

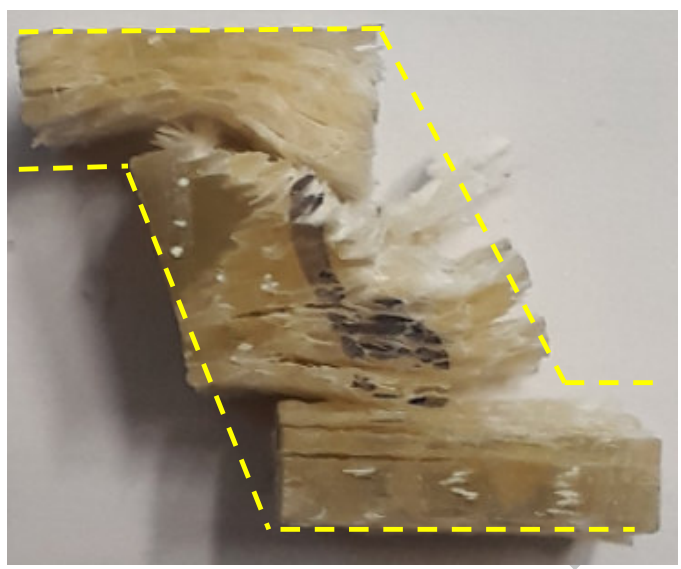

Weft and warp yarns broken

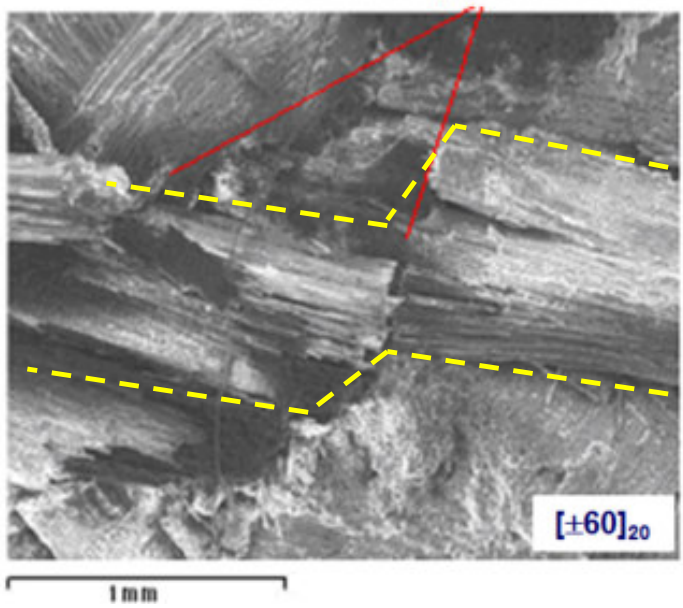

(b) Sliding of composite plies

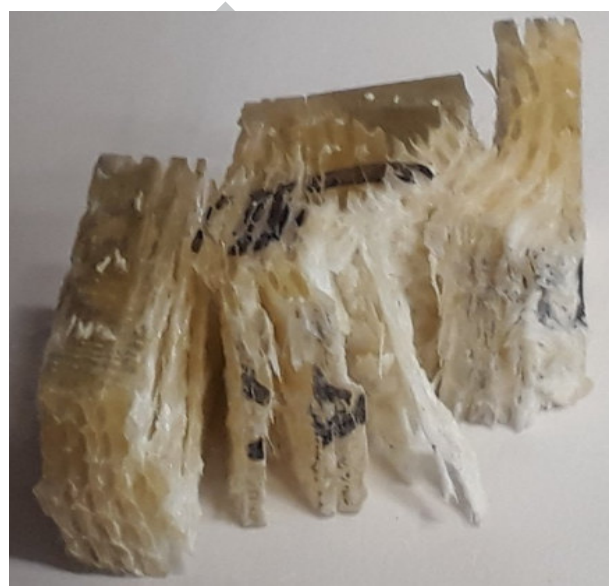

(c) Tested specimens showing composite sliding

Figure 20: SEM analysis of damage mode in tested specimens.

The characterization of heat generation in $[ \pm 60]_{20}$ is significant to understand the damage evolution. To gain information about the heat dissipation vs damage evolution, Figure 21 depicts the superposition of infrared and optical images for the damaged specimen. As can be seen, a hot zone, indicating maximum heat dissipation, appears at the center of the thermal image with a total rupture of plies as observed in the optical image. If the damage becomes more important; this is supported by the important heat dissipation and an abrupt temperature rise during the test. Therefore, moderate heat dissipation release occurs in the course of the fracture of specimens.

The heat dissipation can be determined from the number of pixels associated with their respective temperature values. This is based on the fact that the color of every pixel indicates 
its temperature value, Figure 22. It is found that there is an obvious rise in maximum temperature in the material. Transient heat generation cannot be overlooked in the polymer laminate composites under compressive dynamic tests. Since the glass transition temperature ( Tg) of the epoxy polymer is only about $82^{\circ} \mathrm{C}$ [37], such highly heated effect in the tested composite would result in softening composites and weakened mechanical properties, which favorite the damage. During compressive impact test, an elevation of the temperature till $219^{\circ} \mathrm{C}$ was obtained. When the temperature of specimens exceeds the $\mathrm{Tg}$, the mechanical properties of epoxy deteriorate with changing the polymer state (from rubbery state to glass state) by the mobility of active chains and the chemical reaction. There is a significant relationship between molecular chains, the glass transition temperature and deterioration of mechanical properties $[19,35]$. Finally, the results demonstrated in this work suggest that the damage of specimens under impact test generates an elevation of the temperature and the impact energy was absorbed by the specimen and dissipated as heat with the formation of matrix microcracks, delamination and rupture of fibers.

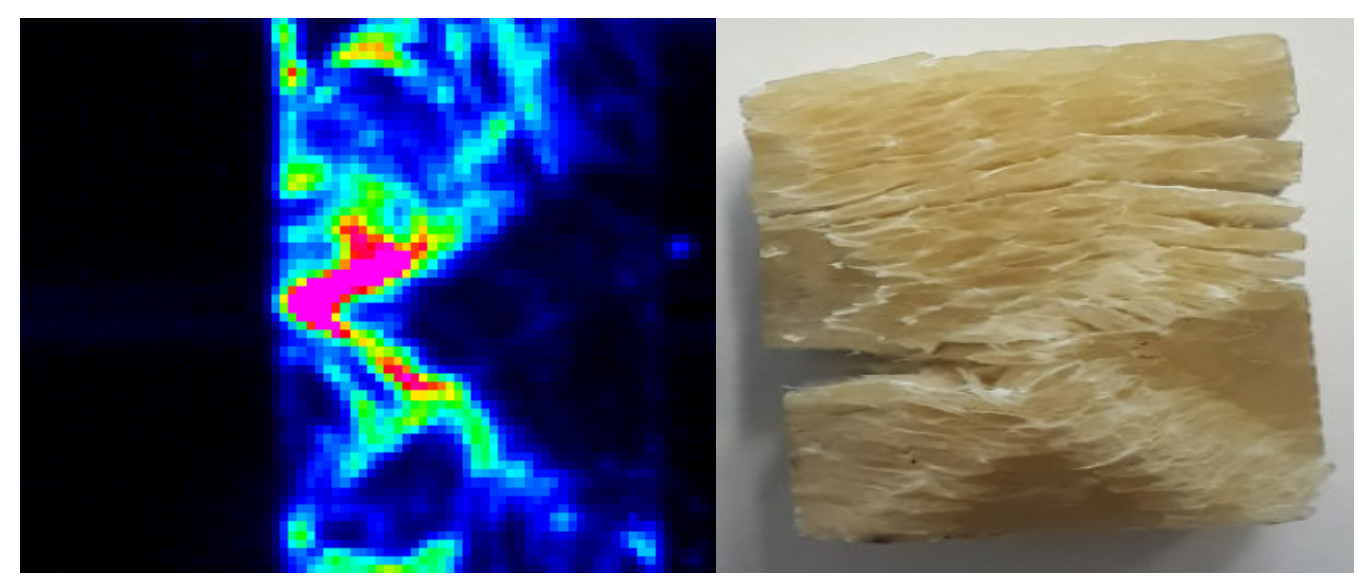

Figure 21: Superposition of infrared and optical images. 

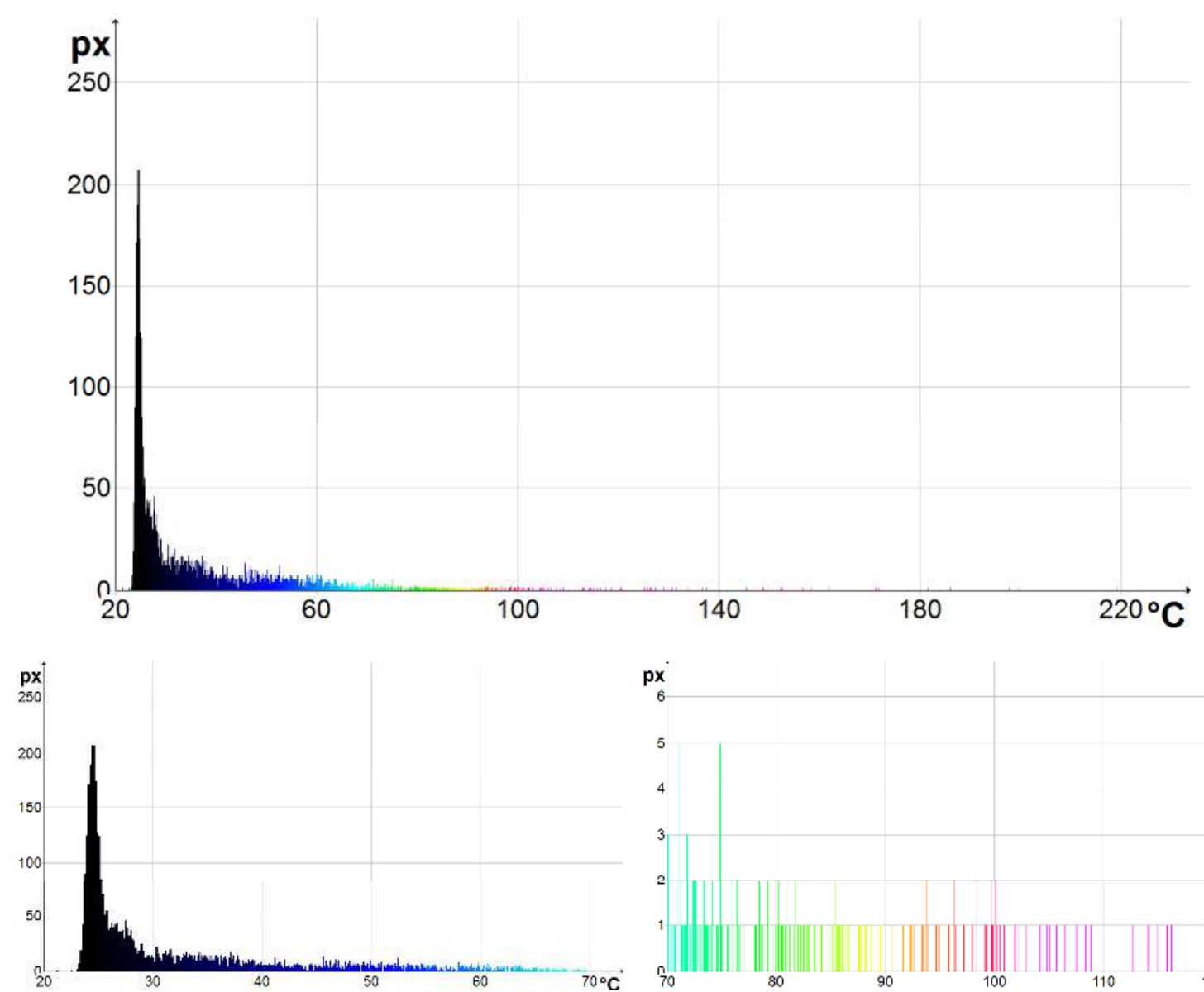

(a) Zoom $[20,70]{ }^{\circ} \mathrm{C}$
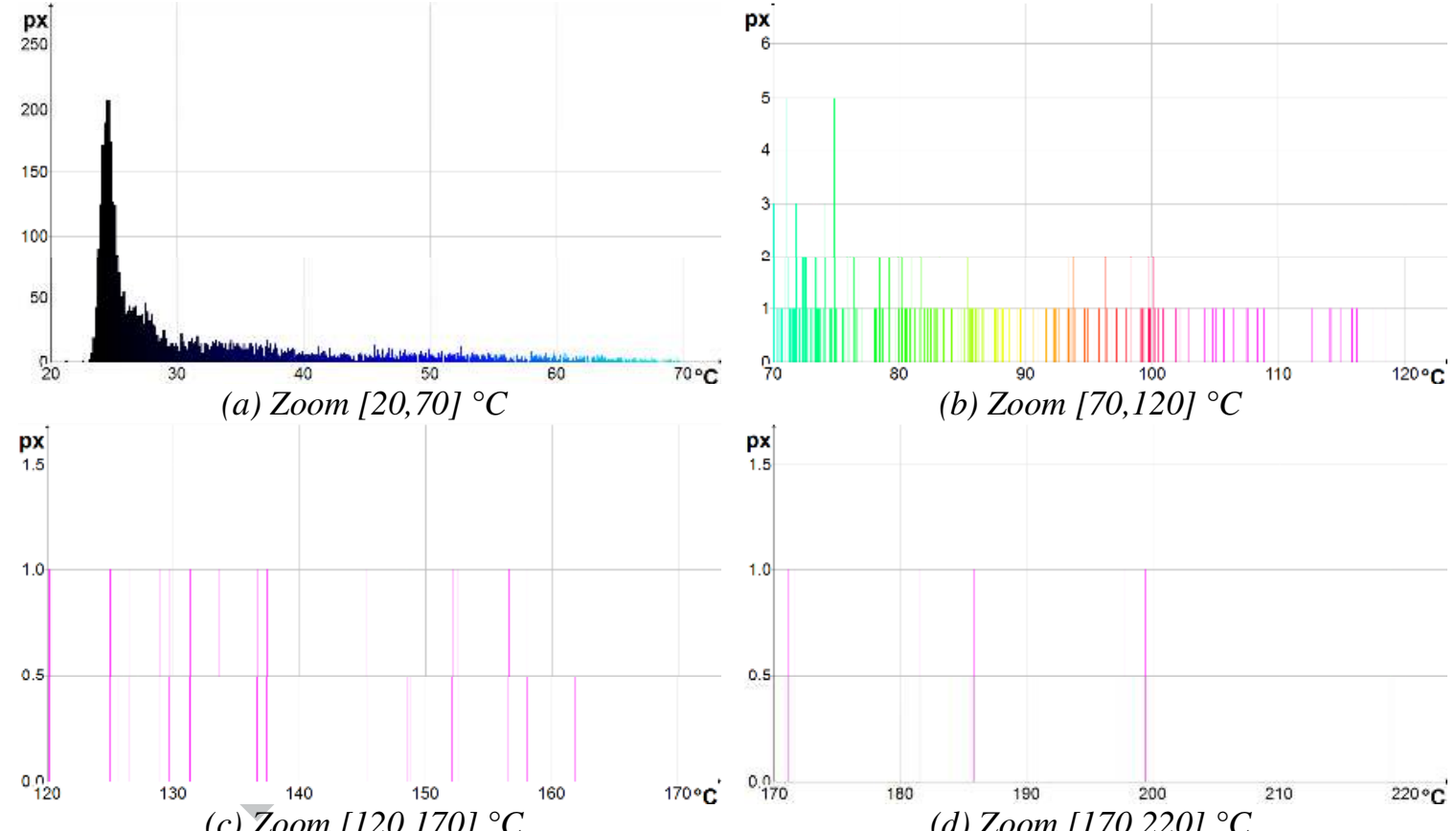

(c) Zoom $[120,170]^{\circ} \mathrm{C}$

(b) Zoom $[70,120]{ }^{\circ} \mathrm{C}$

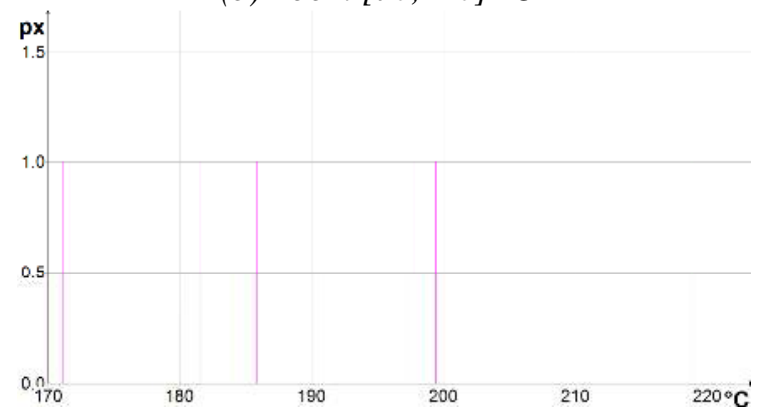

Figure 22: Histogram of temperature distribution in the composite.

\section{Conclusions}

An experimental setup in which simultaneous full-field deformation, damage and temperature measurements were done on the surface of a specimen during dynamic compression tests conducted at different strain rates using Hopkinson bars. The infrared thermal camera was used to detect defects and damage in $[ \pm 60]_{20}$ glass fibers reinforced 
epoxy polymer composites. From the obtained results some remarkable remarks can be made. Results show that:

- During dynamic compression tests on the monitored surface, the composite undergoes the first wave and then heating up because of dissipation of the impact energy. The temperature profile indicates the variation occurs during a short time and their visualization is possible with high-frequency imaging.

- The mechanical impact energy, dissipated as heat is spent in the formation of different damage modes as matrix cracks, delamination, and rupture of fibers.

- For the case of higher strain rates, about $1430 \mathrm{~s}^{-1}$ (1.6bar), there is a drop of interply force, which causes a concentration of stress at the inter-ply zones and which represents the initiation of the damage. This causes a temperature rise detected by the infrared camera.

- When the damage becomes more important; this is supported by the abrupt temperature rise observed in thermal images.

- A hot zone, or many, was observed and coincide with damage area taking the same shape (V-letter in our tests). The whole warm zone was localized at the center of the specimen and coincides with the permanent damage occurred in the composite.

- There is a general agreement between the damage observed as hot area during impact test and the damage detected by rapid camera. With lock-in thermography and the rapid camera shows a satisfactory agreement and allows for a correct identification of size, location and shape of the created area of damage. V-letter like shape is the principle damage form observed in specimens. For the thermal camera, a hot spot with V-shape is also observed during the test with Hopkinson bars. The hot area was localized in the intersection of the two branches of the $\mathrm{V}$ with maximum temperature exceeds $219^{\circ} \mathrm{C}$. Finally, this can be regarded as mutual validation of the techniques for application in the detection of impact damage for high strain rate using Hopkinson bars.

\section{Acknowledgments}

This work was funded by DGA (Direction générale de l'armement - Ministry of Defense, France), MRIS project: Study of the thermomechanical behavior of composites under dynamic loading. The Authors of this paper gratefully acknowledge the financial support of the DGA, France. Acknowledgments have also addressed to Pr. Bruno Mortaigne from DGA. 


\section{References}

[1] Kang JT, Kim C. Impact energy absorption mechanism of largely deformable composites with different reinforcing structures. Fibers and Polymers 2000; 1: 45-54.

[2] Wattrisse B, Muracciole JM, Chrysochoos A. Thermomechanical effects accompanying the localized necking of semi-crystalline polymers. International Journal of Thermal Science 2002; 41: 422-427.

[3] Meola C, Carlomagno GM. Infrared thermography to impact-driven thermal effects. Applied Physics A 2009; 96: 759-62.

[4] Kordatos E.Z, Aggelis DG, Matikas TE. Monitoring mechanical damage in structural materials using complimentary NDE techniques based on thermography and acoustic emission. Composites: Part B 2012; 43: 2676-2686.

[5] Noble JP, Harding J. Temperature Measurement in the Tensile Hopkinson Bar Test. Measurement Science and Technology 1994; 5: 1163-1171.

[6] Arruda EM, Boyce MC, Jayachandran R. Effects of strain rate, temperature and thermomechanical coupling on the finite strain deformation of glassy polymers. Mechanics of Materials 1995; 19: 193-212.

[7] Buckley CP, Harding J, Hou JP, Ruiz C, Trojanowski A. Deformation of thermosetting resins at impact rates of strain. Part I: experimental study. Journal of Mechanics and Physics of Solids 2001; 49: 1517-1538.

[8] Garg M, Mulliken AD, Boyce MC. Temperature rise in polymeric materials during high rate deformation. Journal of Applied Mechanics 2008; 75: 148-155.

[9] Lerch V, Gary G, Herve P. Thermomechanical properties of polycarbonate under dynamic loading. J. De Physique IV 2003; 110: 159-164.

[10] Li Z, Lambros J. Strain rate effects on the thermomechanical behavior of polymers. International Journal of Solids and Structures 2001; 38: 3549-3562.

[11] Mulliken AD. Mechanics of Amorphous Polymers and Polymer Nanocomposites during High Rate Deformation. Massachusetts Institute of Technology, 2006.

[12] Pan ZX, Sun B, Shim VPW, Gu B. Transient heat generation and thermo-mechanical response of epoxy resin under adiabatic impact compressions. International Journal of Heat and Mass Transfer 2016; 95: 874-889.

[13] Regev A, Rittel D. Simultaneous transient temperature sensing of impacted polymers using infrared detectors and thermocouples. Experimental Mechanics 2008; 48: 675-682.

[14] Meola C, Boccardi S, Boffa ND, Monaco E, Petrone G, Ricci F, Carlomagno GM. Learning more on impact damaging of composites with infrared thermography. ICILSM 2016. 22-26 May 2016, Turin Italy. 
[15] Li Y, Yang Z, Zhu J, Ming A, Zhang W, Zhang J. Investigation on the damage evolution in the impacted composite material based on active infrared thermography. NDT\&E International 2016; 83: 114-122.

[16] Gilat A, Kuokkala VT, Seidt JD, Smith JL. Full-Field Temperature Measurement in High Strain Rate Tensile Experiment. ICILSM 2016.

[17] Seidt JD, Kuokkala VT, Smith JL, Gilat A. Synchronous Full-Field Strain and Temperature Measurement in Tensile Tests at Low, Intermediate and High Strain Rates. Experimental Mechanics 2017; 57: 219-229.

[18] Gagnon MA, Marcotte F, Lagueux P, Farley V, Guyot E, Morton V. High-Speed and High-Definition Infrared Imaging for Material Characterization in Experimental Mechanics. Proc. of SPIE 2017; Vol. 10214. doi: 10.1117/12.2262140.

[19] Pan Z, Xiong J, Liang S, Zou M. Transient deformation and heat generation of solid polyurethane under impact compression. Polymer Testing 2017; 61: 269-279.

[20] Rittel D. Transient Temperature Measurement Using Embedded Thermocouples. Experimental Mechanics 1998; 38:2.

[21] Chou SC, Robertson KD, Rainey JH. The effect of strain rate and heat developed during deformation on the stress-strain curve of plastics. Experimental Mechanics 1973; 13: 422432.

[22] Rabin Y, Rittel D. A model for the time response of solid-embedded thermocouples. Experimental Mechanics 1999; 39: 132-136.

[23] Rittel D. On the conversion of plastic work to heat during high strain rate deformation of glassy polymers. Mechanics of Materials 1999; 31: 131-139.

[24] Kendall MJ, Froud RF, Siviour CR. Novel temperature measurement method \& thermodynamic investigations of amorphous polymers during high rate deformation. Polymer 2014; 55: 2514-2522.

[25] Korkut I, Boy M, Karacan I, Seker U. Investigation of chip-back temperature during machining depending on cutting parameters. Materials and Design 2007; 28: 2329-2335.

[26] Shen B, Xiao G, Guo C, Malkin S, Shih AJ. Thermocouple Fixation Method for Grinding Temperature Measurement. Journal of Manufacturing Science and Engineering 2008; 130. doi:10.1115/1.2976142.

[27] Meola C, Carlomagno GM. Impact damage in GFRP: New insights with infrared thermography. Composites: Part A 2010; 41: 1839-1847.

[28] Biot MA. Thermoelasticity and irreversible thermodynamics. Journal of Applied Physics 1956; 27: 240-53. 
[29] Meola C, Carlomagno GM. Infrared thermography to evaluate impact damage in glass/epoxy with manufacturing defects. International Journal of Impact Engineering 2014; 67: 1-11.

[30] Liang T, Ren W, Tian GY, Elradi M, Gao Y. Low energy impact damage detection in CFRP using eddy current pulsed thermography. Composite Structures 2016; 143: 352-361.

[31] Lee B, Walsh B, Won ST, Patts HM, Song JW, Mayer AH. Penetration failure mechanisms of armor-grade fiber composites under impact. Journal of Composite Materials 2001; 35: 1605-1633.

[32] Cheeseman BA, Bogetti TA. Ballistic impact into fabric and compliant composite laminates. Composite Structures 2003; 61: 161-173.

[33] Meola C, Carlomagno GM, Squillace A, Giorleo G. Non-destructive control of industrial materials by means of lock-in thermography. Meas Sci Technol 2002;13: 1583-90.

[34] Duan X, Zhou Y, Jia D, Wang D. Microstructures of ZrO2(3Y) Ceramics after Dynamic Impact. Key Engineering Materials 2007; 353: 1533-1535.

[35] Xuhui H, Youqing H. The Effects of Curing Cycles on Properties of the Epoxy System 3221/RH Glass Fabric Composites. Polymer Composites 2008; 29: 364-371.

[36] Lisle T, Pastor ML, Bouvet C, Margueres P. Damage of woven composite under translaminar cracking tests using infrared thermography. Composite Structures 161 (2017) 275-286.

[37] Axon Comparny. Datasheet of EPOLAM 2020. http://www.axson-technologies.com. 